\title{
Managing customer satisfaction after a product recall: the joint role of remedy, brand equity, and severity
}

\author{
Alexander Mafael ${ }^{1}$ (I) $\cdot$ Sascha Raithel ${ }^{2} \cdot$ Stefan J. Hock ${ }^{3}$ \\ Received: 17 October 2019 / Accepted: 12 July 2021 / Published online: 31 August 2021 \\ (C) The Author(s) 2021
}

\begin{abstract}
Firms struggle to respond to product recalls and manage post-recall customer satisfaction. In three studies, we examine the impact of firms' remedy choice on satisfaction and provide evidence that firms' post-recall remedy efforts are often not optimal. In Study 1 (field study), we estimate the longer-term effects of remedy on different satisfaction metrics and show that offering full remedy is much more important for low and high (vs. medium) brand equity firms, especially when failure severity is high. In Study 2 (experiment), we find further evidence that the positive impact of full remedy on satisfaction is moderated by brand equity in a u-shaped fashion. Finally, Study 3 (experiment) provides further evidence that the relationship between remedy and brand equity is contingent on failure severity. The findings contribute to the literature on firms' management of negative relationship events and provide managers with the empirically grounded 5R guidelines to make better remedy decisions in response to product recalls.
\end{abstract}

Keywords Product recall $\cdot$ Product-harm crisis $\cdot$ Remedy $\cdot$ Brand equity $\cdot$ Severity $\cdot$ Customer satisfaction

Product recalls are product-harm crises wherein products are considered to be defective or even dangerous (Dawar and Pillutla 2000). Recalls result from product failures, sometimes with serious consequences. For example, in 2016 and 2017, IKEA recalled more than 17 million MALM dressers after reports of several deaths among children surfaced because

Alexander Mafael, Sascha Raithel and Stefan J. Hock contributed equally to this work.

Gergana Nenkov served as Area Editor for this article.

Alexander Mafael

alexander.mafael@hhs.se

Sascha Raithel

sascha.raithel@fu-berlin.de

Stefan J. Hock

stefan.hock@uconn.edu

1 Center for Retailing, Stockholm School of Economics, Saltmätargatan 13-17, 11359 Stockholm, Sweden

2 Marketing Department, Freie Universität Berlin, Arnimallee 11, 14195 Berlin, Germany

3 University of Connecticut, 2100 Hillside Road, Storrs, CT 06269, USA the dressers could tip and fall if they were not fastened to the wall (Nadolny 2020).

Different firms often offer different remedies for the same type of product failure. For example, while Samsung offered to replace their Galaxy phones (full remedy) after reports of explosions due to battery overheating, Apple only offered to repair their iPhone batteries for a fee (partial remedy), sparking outrage among consumers about unfair treatment (Nellis 2017).

Firms' decision on the appropriate remedy is crucial, as product recalls are disruptive negative events that alter the relationship between customers and firms significantly for a prolonged period (Harmeling et al. 2015). Yet, firms often struggle to offer the appropriate remedy because there is little empirical guidance (Cleeren, Dekimpe and van Heerde 2017). Table 1 illustrates this study's contributions to the existing literature on product recalls.

First, while previous research on product recalls exclusively focuses on the impact of timing of the recall announcement or advertising spending on product sales or stock prices, we demonstrate that full (vs. partial) remedies can have a positive impact on customer satisfaction. Customer satisfaction (henceforth: satisfaction) is defined as customers' overall assessment of the perceived quality and value of the firm's 


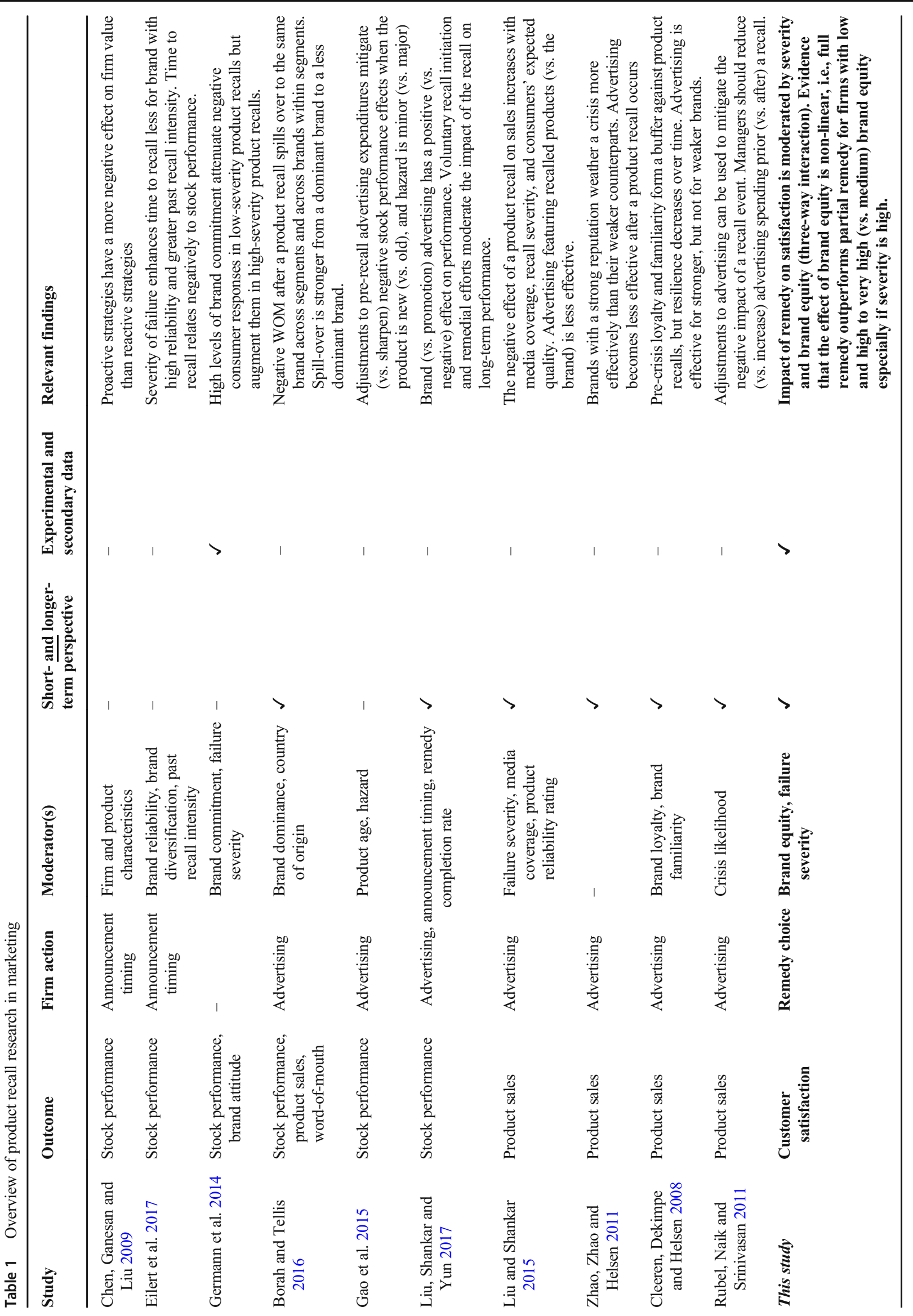


offerings, as well as how these offerings conform to customers' expectations (Fornell et al. 1996).

Second, and more importantly, we show that remedy choice and pre-recall brand equity (henceforth: brand equity) jointly influence satisfaction. Specifically, our study suggests a complex, non-linear interactive effect of remedy and brand equity on satisfaction, such that the effect is larger for firms with low and high brand equity compared to medium brand equity firms.

Third, we provide more fine-grained insights and show that the interactive effect of remedy and brand equity is most pronounced when failure severity (henceforth: severity) is high. This finding extends existing research on the link between brand equity and severity by showing that the effect of severity on satisfaction is not only contingent on brand equity (e.g., Germann et al. 2014; Roehm and Brady 2007), but also on firms' remedy choices in response to the failure.

Fourth, we use field data to illustrate the longer-term impact of remedy choice on four different satisfaction metrics. This study shows that full remedy is more important for low and high brand equity firms than for medium brand equity firms. Offering full remedy, low and high brand equity firms are more likely to prevent larger satisfaction losses, shorten the satisfaction recovery time, and stabilize satisfaction at higher levels. This is the first study to (1) offer such a holistic view and (2) derive consumer-based strategy (Hamilton 2016).

Fifth, with the exception of Germann et al. (2014), previous research on product recalls relies either on secondary or experimental data. We, on the other hand, utilize both secondary and experimental data to bridge this existing gap and provide theoretically and managerially relevant insights to the emerging, which cannot be achieved through one data source alone (Davis, Golicic and Boerstler 2011; Hamilton 2016).

\section{Conceptual background}

\section{The influence of remedy on satisfaction}

The negative impact of product recalls is well established. Product recalls can transform the relationship between customers and firms (Harmeling et al. 2015). Extant research suggests that adequate compensation is the key ingredient to recover satisfaction (Gelbrich and Roschk 2011). In particular, firms can respond through intangible (e.g., apologizing, Bonifield and Cole 2007) or tangible (e.g., offering a remedy, Liu et al. 2016) compensation.

While customers' response to firms' communicative efforts has received considerable attention in the literature (see Cleeren et al. 2017 for an excellent overview), the role of firms' remedial efforts remains unclear. For example, Liu et al. (2016) investigate determinants of firms' remedy choices and find that full (vs. partial) remedy is less likely when CEOs receive greater cash compensation or have longer tenure in the position.
However, they do not study the impact of remedy choice on customers. Liu et al. (2017) find that remedy completion rate (i.e., the percentage of products fixed) weakens the negative effect of recall volume on firm value, but they do not investigate different remedies and their effect on customers.

In summary, the existing research on firm compensation after a product recall (1) leaves room for speculation regarding firms' optimal remedy choice and (2) does not examine how a firm's remedy choice affects satisfaction in the short and longer term. In general, firms can either offer full remedy, i.e., the firm is responsible for fixing the issue, such as free repair, exchange, or refund, or partial remedy, i.e., the firm shifts the responsibility for fixing the issue to the customers, such as a free repair kit or a rebate on a replacement. This definition mirrors other classifications of responses to product-harm crises, such as 'accommodative' versus 'defensive' (Bundy and Pfarrer 2015) or 'unambiguous support' versus 'stonewalling' (Dawar and Pillutla 2000) and conceptualizes compensatory efforts after a product recall (Liu et al. 2016).

A firm's response strategy should meet customer expectations to have a positive impact on satisfaction, while falling short of expectations should have a negative impact (Hock and Raithel 2020). From the perspective of expectancydisconfirmation theory (Oliver 1980), it is important to conceptualize the different expectations of consumers. For example, consumers have lower expectations for a product from a low reputation firm (Rhee and Haunschild, 2006), while expecting more from a firm with a strong reputation (Brady et al. 2008). Considering the role of firm characteristics, such as brand equity, is therefore vital when examining the role of remedy.

\section{The role of brand equity during a product recall}

Brand perceptions are important for managing crises (e.g., Bundy et al. 2017; Brady et al. 2008; Khamitov, Grégoire and Suri 2020). Customer-based brand equity captures customers' accumulated beliefs about brand performance (Keller 1993), and can determine how customers respond to firm actions following a negative relationship event, because it shapes customers' expectations towards the firms' behavior (Dawar and Pillutla 2000; Walsh, Winterich and Mittal 2010). For example, a high-equity brand's favorable associations may lead customers to expect strong benefits from the brand's offerings (Chandon, Wansink and Laurent 2000). As such, a performance failure by a strong brand may result in serious disappointment. Prior work in the field of social approval theorizes that managers base their actions primarily on how external stakeholders perceive the firm before the crisis (Bundy and Pfarrer 2015). Therefore, it is important to investigate how brand equity moderates the influence of remedy on satisfaction. In addition, product failures are not homogeneous events and may differ in the extent to which they are likely to affect consumers. As a result, the extent to which the relationship between remedy and brand equity influences customer 
satisfaction may depend on characteristics of the failure, such as severity (Germann et al. 2014; Keiningham et al. 2014).

\section{The role of severity}

While some product failures can cause considerable harm to customers (e.g., recalling a food processor because the loose blade can severely hurt people), other recalls occur because of a minor inconvenience (e.g., recalling a fridge because a warning sign was not clearly visible). Consequently, product failures are not uniform in their potential impact on the equity balance in customer-firm relationships. Failure severity is defined as the actual and potential damages caused by the recalled product (Cheah, Chan and Chieng 2007). Research suggests that a certain degree of severity is necessary for a recall to affect customers because a severe failure signifies a high probability of damages (Germann et al. 2014). Consequently, research on service failure severity finds that the greater the severity, the greater the impact on satisfaction (Keiningham et al. 2014). These findings are supported by the literature on relationship transgressions suggesting that more severe transgressions are associated with less forgiveness towards the transgressor (Fincham, Jackson and Beach 2005). Thus, a certain degree of severity is necessary for the recall to affect satisfaction and, more importantly, to necessitate appropriate remedies. This mechanism is grounded in the fact that severe recalls are performance failures that oppose consumers' expectations (Smith, Bolton and Wagner 1999).

\section{Hypotheses development}

The main focus of this paper is to provide empirical insights into the interactive effects between remedy, brand equity, and severity on satisfaction. We draw on the expectancy-disconfirmation literature and reactive equity theory to develop the relationships between these concepts. Therefore, we provide a set of formal hypotheses for these interactive effects next. Given the focus on these joint effects, we do not provide formal hypotheses for the main effects of remedy, brand equity, and severity, but we report all main and total effects in our analyses.

\section{The interactive effect of remedy and brand equity on satisfaction (H1)}

Satisfaction mirrors how firm actions have (dis)confirmed customers' expectations over time (Oliver 1997). Expectancydisconfirmation literature suggests that the level of expectation that customers hold towards firm behavior depends on their beliefs and associations with the firm (Niedrich, Kiryanova and Black 2005). Since brand equity captures customers' associations with brands and corresponds to expectations towards quality and performance (Keller 1993), we propose that customers assessment of remedy choice is influenced by brand equity.

Any performance failure creates an equity imbalance in the customer-firm relationship (Fehr and Gächter 2000). Following a product recall, firms can try to restore balance by offering an adequate remedy. Full remedies (e.g., free repairs), are more likely to restore equity balance, because they fully fix the problem, helping to restore trust and satisfaction (Siegel and Vitaliano 2007). Partial remedies (e.g., free do-it-yourself repair kits), on the other hand, shift the responsibility of fixing the issue to the customers and present an increased level of risk (e.g., wrongful use of repair kit). Customers perceive such firm behavior as unfair (Ingram, Skinner and Taylor 2005) because partial remedies are less likely to restore equity balance. As indicated previously, brand equity shapes customers' expectations towards the firm's behavior (Dawar and Pillutla 2000; Walsh, Winterich and Mittal 2010).

High brand equity Firms with high brand equity are more likely to be perceived as firms that deliver high quality, reliable products (Hess 2008; Rindova et al., 2005; Roehm and Brady 2007). If such firms only offer partial remedy, it could contradict customers' high expectations and motivate negative responses (Grégoire and Fisher 2008; Grégoire et al. 2009), because it suggests that the firm does not believe it needs to provide full compensation to restore balance (Grégoire and Fisher 2006; Oliver and Westbrook 1993). In comparison, offering full remedy reassures customers' expectations and provides a motivation to restore relational balance and reconcile the cognitive dissonance. At the same time, high brand equity may act as a buffer against negative responses when the firm only offers partial remedy (Ahluwalia et al., 2000). In addition, the buffering quality of high brand equity may weaken the negative impact of the failure on consumers' confidence in a product's performance (Dean, 2004; Erdem and Swait, 1998). While customers are likely to appreciate the firms' effort in offering full remedy, high brand equity firms may benefit less from offering full remedy.

Low brand equity Customers associate low brand equity firms with lower quality and thus are more likely to appreciate any remedy. For low brand equity firms, a product failure poses a survival threat as it may invoke outright disapproval by customers in the future, and low brand equity does not provide the necessary buffer against disapproval (Dawar and Pillutla 2000). Therefore, low brand equity firms are more likely to restore satisfaction if they handle the failure unexpectedly well and offer full remedy (De Matos, Henrique and Rossi 2007; McCullough, Berry and Yadav 2000).

Building on these arguments, we predict that consumers will be more satisfied with full (vs. partial) remedy and that firms with low brand equity can reap additional benefits from offering full remedy while firms with high brand equity cannot. 
H1 Brand equity moderates the effect of remedy on satisfaction negatively, such that offering full (vs. partial) remedy mitigates the negative effect of the recall on satisfaction more for firms with lower brand equity than for firms with higher brand equity.

\section{The non-linear interactive effect of remedy and brand equity on satisfaction (H2)}

Previous research indicates that the structural relationship between brand equity and customer satisfaction is not linear, but in fact concave (Homburg, Koschate and Hoyer 2005; Loomes and Sugden 1986). This effect most likely arises because customer expectations towards firm actions are more pronounced for firms that are associated with highly superior or inferior quality (i.e., very high and very low brand equity firms) than for firms with average quality (i.e., medium brand equity firms). The greater the negative/positive disparity between outcome and expectations, the greater consumers' disappointment/contentment (Oliver and DeSarbo 1988).

Specifically, we propose that firms with very high and very low (vs. medium) brand equity suffer more (vs. less) from offering partial (vs. full) remedy, and that customers' dissatisfaction increases with a widening negative gap between expectations and experience (Inman, Dyer and Jia 1997; Loomes and Sugden 1986). Thus, firms with very high and very low (vs. medium) brand equity should experience a stronger decrease in satisfaction if they only offer partial remedy. For firms with very high brand equity, the disconfirmation of customers' expectations becomes too prominent, making reconciliation difficult. The buffering effect of high brand equity eventually turns into a boomerang effect. For firms with very low brand equity, offering partial remedy may serve as the tipping point, leading to customers' losing any remaining trust in the brand. Compared to medium-brand equity firms, this leads to a gap between the level of satisfaction that could have been achieved had the firm opted for full remedy, and this gap becomes larger at the margins of brand equity.

These effects become more pronounced in comparison to medium brand equity firms because for these firms, consumers hold rather ambiguous expectations towards firm behavior. In the case of a recall, they are therefore neither positively surprised nor disappointed if the firm offers either full or partial remedy. In both cases, consumers may however regret why they did not buy from the high equity (i.e., the brand that is associated with superior quality) or low equity (i.e., the brand that is associated with lower costs) brand (Raithel, Mafael and Hock 2020).

H2 Brand equity moderates the effect of remedy on satisfaction non-linearly (u-shape), such that offering full (vs. partial) remedy mitigates the negative effect of the recall on satisfaction more for low and high brand equity firms than for medium brand equity firms.

\section{The interactive effect of remedy, brand equity, and severity on satisfaction ( $\mathrm{H} 3 \mathrm{a}$ and $\mathrm{H} 3 \mathrm{~b})$}

We argue that high (vs. low) failure severity aggravates (mitigates) the impact of remedy on satisfaction for both low and high (vs. medium) brand equity firms. Following our previous argument about the linear and non-linear nature of the remedy*brand equity interaction, we expect a widening gap in satisfaction between offering full and partial remedy for high and low (vs. medium) brand equity firms.

Reactive equity theory suggests that customers perceive an imbalance in their relationship with the firm after a product recall and that the imbalance is greater when the failure is more severe (Smith, Bolton and Wagner 1999). Severity refers to a customer's perceived intensity of a failure - the more severe the failure, the greater the customer's perceived loss (Weun, Beatty and Jones 2004). In this situation, it is even more important that the firm offers full remedy to restore satisfaction (Oliver 1997), because a severe product recall often corresponds with incidences of serious harm to customers (Germann et al. 2014) and draws public attention (Korkofingas and Ang 2011). In turn, when severity is low, customers are more likely to be satisfied with partial remedy because the perceived equity loss and the threat of suffering harm is low. Hence, severity should also influence the joint impact of remedy and brand equity on satisfaction:

When severity is low and brand equity is high, consumers are less worried about the failure and high brand equity may serve as a buffer-even when the firm only offers partial remedy. Offering full remedy may even be interpreted as overconforming to expectations and raise doubts about the firm's sincerity and true motives (Bundy and Pfarrer 2015, Dawar and Pillutla 2000, Raithel and Hock 2021). However, if severity is high, these firms need to offer full remedy to meet customers' high expectations and avoid feelings of revenge and betrayal (Eccles et al. 2007; Grégoire et al., 2009). Otherwise, customers reconcile the contradiction caused by the gap between their high expectations and their experience by reevaluating (i.e., downgrading) their relationship with the firm - leading to a boomerang effect.

When severity is low and brand equity is low, consumers are less worried, have lower initial expectations, and thus do not expect firms to offer full remedy as these firms are not associated with high quality. This situation even entails an opportunity for low equity firms to influence satisfaction positively if they handle the failure unexpectedly well (cp. service recovery paradox, De Matos et al., 2007). However, if severity is high, the existence of these low equity brands is threatened because not offering full remedy suggests that the brand does not even invest in quality when there are severe issues that 
may threaten consumers' health. This behavior can provoke outright disapproval by customers and further diminishes beliefs in the quality of the firm's offerings (Dawar and Pillutla 2000), thus leading to a potential wipe-out effect.

For medium brand equity firms, there is much less at stake compared to both low and high brand equity firms. Due to customers' ambivalent experiences with, and expectations towards the firm, any gap between experience and expectation is smaller, independent of severity and remedy. First, both buffering and boomerang effects are weaker compared to the high brand equity firms, mainly because consumers relationship with these brands lack motivational force for or against the brand (Park, Eisingerich and Park 2013). Second, compared to low brand equity firms, medium brand equity firms are less likely to receive outright disapproval by choosing partial remedy when severity is high. Thus, medium brand equity firms may be able to rely on this ambivalence effect because they have much less to gain or to lose.

In sum, the linear interaction remedy*brand equity (H1) becomes weaker, and the non-linear interaction remedy*brand equity^2 (H2) becomes stronger:

H3a Severity moderates the negative linear interactive effect of remedy and brand equity on satisfaction positively (i.e., weaker linear interaction), such that offering full (vs. partial) remedy mitigates the negative effect of the recall on satisfaction less (more) for firms with lower brand equity than for firms with higher brand equity when severity is high (low).

H3b Severity moderates the non-linear interactive effect of remedy and brand equity on satisfaction positively (i.e., stronger non-linear interaction and more pronounced u-shape), such that offering full (vs. partial) remedy mitigates the negative effect of the recall on satisfaction more (less) for low and high brand equity firms (vs. medium brand equity firms) when severity is high (low).

Table 2 summarizes the hypotheses and the associated empirical studies.

\section{Overview of empirical studies}

In Study 1 (secondary data), we investigate the longer-term effects of remedy on satisfaction. We provide a comprehensive set of four different satisfaction metrics that can help managers understand the impact of the product recall on satisfaction in more detail. We find that full remedy is more important for low and high (vs. medium) brand equity firms. Two follow-up experiments address the limited internal validity of the field study. Study 2 (experiment) provides further evidence that the positive impact of full remedy on satisfaction is moderated by brand equity in a non-linear fashion. Finally,
Study 3 (experiment) shows the moderating effect of severity on the relationship between remedy and brand equity, such that the effect is stronger when failure severity is high. Table 2 provides an overview of the three studies.

\section{Study 1: The longer-term impact of remedy on satisfaction}

Study 1 examines the longer-term evolution of satisfaction in response to remedy offers for real-world product recalls. To model the temporal dynamics of the data, we define four different satisfaction metrics and investigate them during a twomonth period following the product recall to help managers better understand (1) the longer-term impact of the product recall on satisfaction and (2) how quickly firms recover based on their remedy choice.

\section{Data sources, measures, and sample}

To alleviate concerns about demand effects, we combine two unrelated data sets:

Remedy We collected standardized data on product recalls from January 2008 to February 2020 from the CPSC's website. Based on the recall report, we construct the dummy variable Remedy that has a value of 1 if the firm offered full remedy (i.e., is responsible for fixing the issue, such as a free repair, exchange, or refund) and 0 if the firm offered partial remedy (i.e., shift the responsibility for fixing the issue to their customers, such as free repair kits).

Brand equity The YouGov Group monitors about 1500 brands in the U.S. by surveying up to 4000 consumers daily. Respondents are randomly drawn from a panel of up to 2 million adults (Luo, Raithel and Wiles 2013). YouGov's BrandIndex tool includes six customer-based brand performance indicators that closely mirror the customer-based brand equity model (Keller 2001): (1) Satisfaction ("Are you a recent satisfied or dissatisfied customer?"), (2) Quality ("Is the brand of good or poor quality?"), (3) Impression ("Do you have a generally positive or negative feeling about the brand?"), (4) Value ("Do you associate the brand with good or poor valuefor-money?"), (5) Recommendation ("Would you recommend the brand to a friend?"), and (6) Workplace reputation ("Would you be proud or embarrassed to work for the brand?"). Respondents either agree with the positive or the negative statement for each question. For each brand and day, we calculated the net rating scores of the six indicators by taking the differences of the number of respondents who agreed with the positive statement and the number of respondents who agreed with the negative statement, and divided the result by the total number of respondents, including neutral 
Table 2 Overview of the research hypotheses and studies.

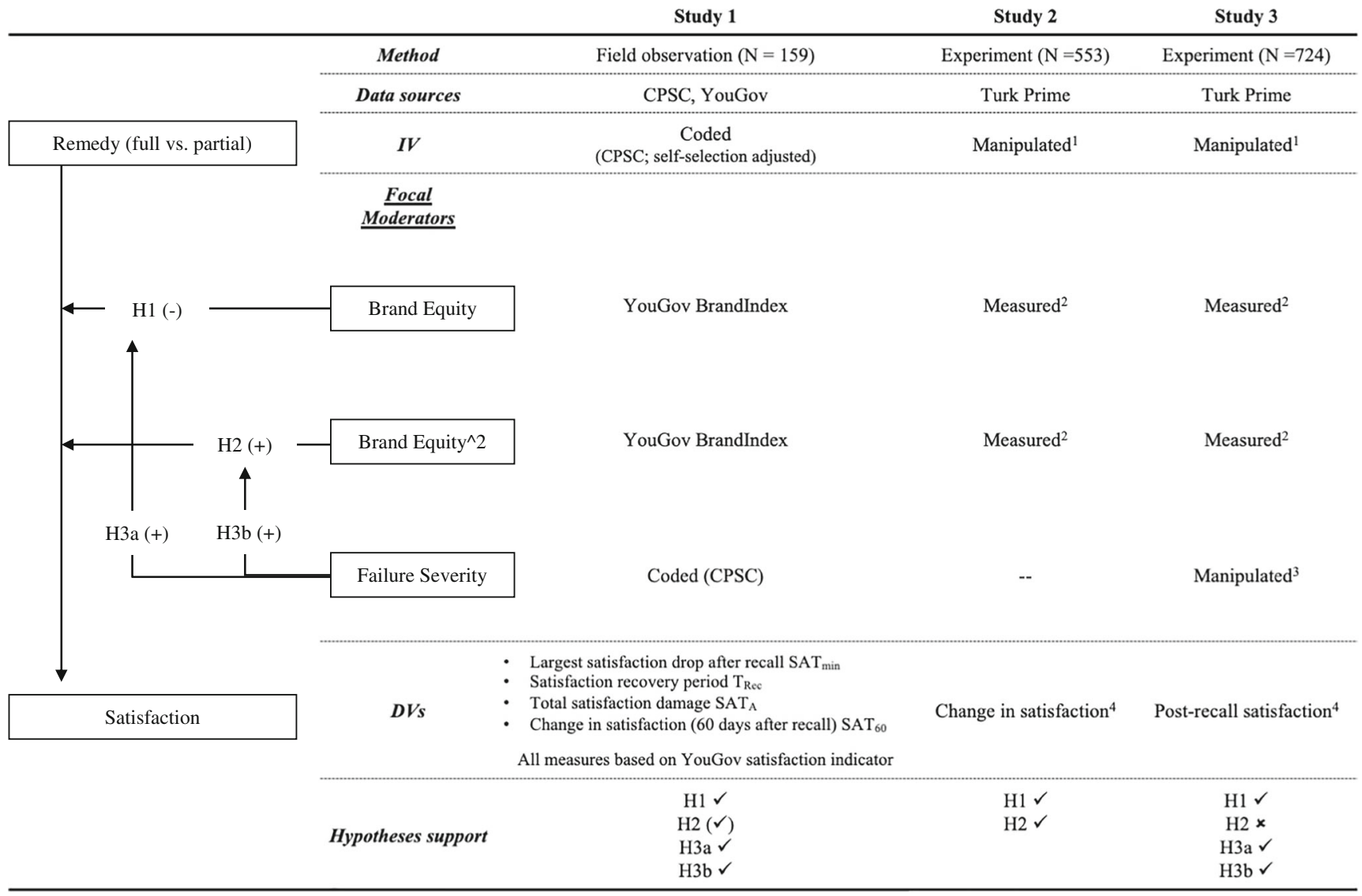

raters. As a measure for the moderator Brand equity, we use the composite factor score of the averages of the six daily indicator scores measured on days $(-30,-1)$ prior to the recall date $(\alpha=.93$, AVE $=83.7 \%)$. To model the suggested non-linear relationship, we include the quadratic term Brand Equity 2 .

Severity We code Severity based on information from the CPSC as 1 if there is a high risk of injury (e.g., fire, fire-related burns, explosion, death) and 0 if there is a low risk (else).

Satisfaction We use YouGov's satisfaction indicator ("Are you a recent satisfied or dissatisfied customer?"), which is a valid predictor of firm performance (e.g., stock price, Colicev et al. 2018; Malshe, Colicev and Mittal 2020). For each brand and day, we calculated the net satisfaction score (see above). Following Luo et al. (2013), we apply the Hodrick-Prescott filter (Hodrick and Prescott 1997) to smooth the satisfaction time series. The filter technique decomposes the time series variable into a trend and noise component, allowing us to use the trend component as a measure for satisfaction. Web Appendix A provides details. To cover any short- and longer-term satisfaction effects, such as an immediate satisfaction drop and the subsequent satisfaction recovery, we study satisfaction effects for the $[0 ; 60]$ post-event days window. We examine the dynamics of satisfaction by calculating the difference between post-recall and pre-recall satisfaction. Prerecall satisfaction is measured by the average pre-recall satisfaction score (days -30 to -1 ). To describe the dynamics in post-recall satisfaction comprehensively, we define four metrics (Fig. 1 illustrates these metrics):

$\boldsymbol{S A} \boldsymbol{T}_{\boldsymbol{m} \text { in }}$ Represents the lowest satisfaction score or "largest drop" in satisfaction between post-recall event days 0 and day 60. Although this metric indicates the maximum damage to satisfaction, it does not account for the sustainability of this damage. We calculate additional metrics for this purpose.

$\boldsymbol{T}_{\boldsymbol{R} e \boldsymbol{c}}$ This metric describes how many days it takes until satisfaction has fully recovered. We define this variable as the post-recall day of satisfaction reversal to the pre-recall satisfaction level on day 0 after the satisfaction score has experienced the minimum satisfaction value $S A T_{\text {min }}$. The larger this metric is, the longer it takes before satisfaction reaches prerecall levels. If the satisfaction score does not reach pre-recall levels, we define $T_{\text {Rec }}=61$.

$\boldsymbol{S A} \boldsymbol{T}_{\boldsymbol{A}}$ To measure the total satisfaction damage, we calculate the net satisfaction effect between event days 0 and 60 . This 
metric is defined as the difference of the post-recall satisfaction area that falls above pre-recall satisfaction and the postrecall satisfaction area that falls below the baseline satisfaction score (see shaded areas in Fig. 1).

$\boldsymbol{S A} \boldsymbol{T}_{\boldsymbol{6} \boldsymbol{0}}$ To measure the long-term effect of the recall on satisfaction, we calculate the difference between satisfaction on event day 60 and pre-recall satisfaction.

Sample We eliminate overlapping recall events (i.e., two or more recalls within 100 days) to minimize confounding effects from multiple events, alleviating concerns about the possibility that a prior recall might affect remedy decisions following another product recall. After merging the two databases we identify 159 product recalls involving 60 brands for the period from January 2008 to February 2020. Remedy choice is distributed almost equally in the sample: 81 (78) firms offered full (partial) remedy. For example, IKEA offered customers a full refund (i.e., full remedy) in response to a wide-spread recall of MALM dressers that could tip over. Black and Decker, on the other hand, offered customers a repair kit (i.e., partial remedy) to replace a faulty cover on their electric blowers. Both full remedy (e.g., IKEA, DeWalt, Quiksilver) and partial remedy (e.g., Black and Decker, Westinghouse) occur across different industries.

\section{Empirical strategy}

Addressing endogeneity Firms choose their remedy strategically (e.g., Liu et al. 2016), so we need to adjust the observational data for this self-selection bias. Brand- and recall-level idiosyncrasies (e.g., brand equity, failure hazard, recall volume) can influence both remedy choice and satisfaction directly, thereby obscuring the causal effect of remedy on satisfaction. This study uses Propensity Score Matching (PSM; Rosenbaum and Rubin 1983; Stuart 2010) to address this concern. Here, the propensity score is the probability that a firm offers full (vs. partial) remedy given the value of the covariates. Of the 81 treatment observations (firms offering full remedy), we had to exclude eight observations which fall outside the common support region, i.e., control observations (firms offering partial remedy) with a similar propensity score do not exist in the sample. This study applies the one-to-one estimator to match each of the remaining 73 treatment observations (full remedy) with one control observation (partial remedy) that was selected by propensity score similarity (here: similar probability that a firm will offer full remedy). Accordingly, the matched sample size becomes $N=146$ (73 treatment and 73 control units). Some of the control observations can be used multiple times if their propensity score is most similar to more than one treatment observation. The various fit criteria suggest that the PSM reduces self- selection bias. Web Appendix B outlines all modeling details of the PSM, shows the probit regression results, illustrates the various tests of common support, and the balancing property before and after matching.

Model and estimation We extract the frequency weights to rebalance the observations according to the PSM results. This re-weighting of treatment and control units allows drawing inferences (Morgan and Harding 2006) and is particularly useful in combining PSM with other methods such as regression (Nichols 2007). To test our hypotheses, we estimate a quantile (median) regression model for each satisfaction metric. We use quantile regression to get more robust estimates compared to OLS, because the satisfaction metrics have partially heavy tail distributions, outliers, and different variances between treatment groups (Koenker and Bassett 1978). ${ }^{1}$ For each satisfaction metric we present the (1) linear model (only linear term Brand Equity) as well as the (2) non-linear model (including the quadratic term Brand Equity ${ }^{\wedge}$ ):

(1)

$$
\begin{aligned}
\text { Satisfaction }_{i}= & \beta_{1 i}+\beta_{2 i} \cdot \text { Remedy }+\beta_{3 i} \cdot \text { Brand Equity } \\
& +\beta_{4 i} \cdot \text { Remedy*Brand Equity } \\
& +\beta_{5 i} \text {.Severity }+\beta_{6 i} \text {.Severity*Remedy } \\
& +\beta_{7 i} \cdot \text { Severity*Brand Equity } \\
& +\beta_{8 i} \cdot \text { Severity*Remedy*Brand Equity } \\
& +\varepsilon_{i}
\end{aligned}
$$

(2)

$$
\begin{aligned}
& \text { Satisfaction }_{i}=\beta_{1 i}+\beta_{2 i} \cdot \text { Remedy }+\beta_{3 i} \cdot \text { Brand Equity } \\
& +\beta_{3 b i} \text { Brand Equity }{ }^{2} \\
& +\beta_{4 i} \cdot \text { Remedy*Brand Equity } \\
& +\beta_{4 b i} \text { Remedy }^{*} \text { Brand Equity }{ }^{2} \\
& +\beta_{5 i} \cdot \text { Severity }+\beta_{6 i} \cdot \text { Severity } * \text { Remed } y \\
& +\beta_{7 i} \text { Severity*Brand Equity } \\
& +\beta_{7 b i} \text {. Severity*Brand Equity }{ }^{2} \\
& +\beta_{8 i} \cdot \text { Severity*Remedy*Brand Equity } \\
& +\beta_{8 b i} \text {.Severity*Remedy*Brand Equity }{ }^{2} \\
& +\varepsilon_{i}
\end{aligned}
$$

\footnotetext{
${ }^{1}$ In the subsequent section "Results" shows model-free evidence. We discuss alternative model specifications in Web Appendix F.
} 


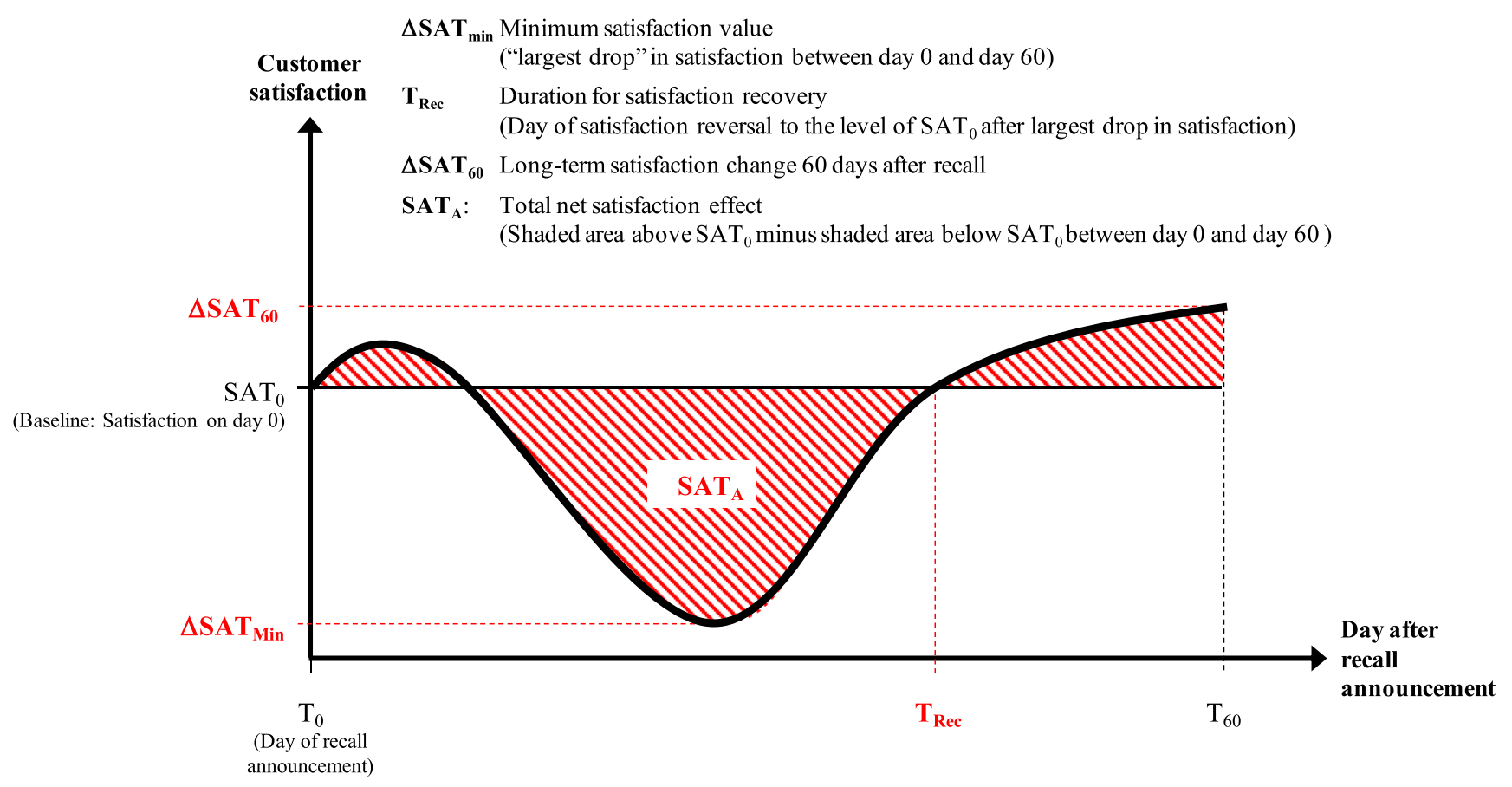

Fig. 1 Visualization of customer satisfaction metrics (Study 1)

Satisfaction $_{i}$ represents the four satisfaction metrics $S A T_{\text {min }}$, $T_{R e c}, S A T_{A}$, and $S A T_{T 60}$. We expect that $\beta_{4 i}$ is negative (H1), $\beta_{4 b i}$ is positive (H2), $\beta_{8 i}$ is positive (H3a), and $\beta_{8 b i}$ is positive $(\mathrm{H} 3 \mathrm{~b})$. The quantile regressions are estimated with heteroscedasticity-consistent standard errors.

\section{Results}

Web Appendix C shows the descriptive statistics and correlations of model variables for the unadjusted sample (Table $\mathrm{C} 1$ ) and the self-selection adjusted sample (Table $\mathrm{C} 2$ ). We first summarize model-free evidence using the unadjusted sample. Then, we discuss in detail the quantile regression results using the self-selection adjusted sample. Finally, we summarize the results of an alternative self-selection adjusted model specification.

Model-free evidence Table D1 in Web Appendix D shows model-free evidence using the unadjusted sample of $159 \mathrm{ob}-$ servations and by dividing the brand equity variable into three equally spaced percentiles: $\mathrm{N}_{\text {Low } \mathrm{BE}}=53, \mathrm{~N}_{\text {Medium } \mathrm{BE}}=53$, $\mathrm{N}_{\mathrm{High} \mathrm{BE}}=53$. Full remedy increases recovery speed and reduces total satisfaction damage best if severity and brand equity are low, whereas full remedy limits total satisfaction damage and restores long-term satisfaction better than partial remedy if severity and brand equity are high. This simplified model provides initial evidence for the complex interactions of remedy, severity, and brand equity.
Quantile (median) regression results for the adjusted sample Table 3 shows the linear and non-linear quantile regression results for the four satisfaction metrics. To facilitate interpretation of the non-linear moderation effects of brand equity, Fig. 2 visualizes the full vs. partial remedy effects across the bandwidth of observed brand equity levels, grouped by low and high severity events. The spotlight analysis in Web Appendix E outlines zones of significant effect differences between remedy types.

Remedy*Brand Equity H1 (- $)^{2}$ In line with H1, we find that brand equity moderates the effect of remedy on satisfaction. Table 3 shows that this interaction effect is significantly negative for all four satisfaction metrics in the linear model and two of four satisfaction metrics in the non-linear model. Specifically, we find that low (vs. high) brand equity firms offering full remedy prevent a larger satisfaction drop $\left(\mathrm{SAT}_{\min }: \mathrm{b}=-.028, p<.001\right.$ and $\left.\mathrm{b}=-.017, p>.10\right)$, decrease recovery time $\left(\mathrm{SAT}_{\text {rec }}: \mathrm{b}=7.399, p<.01\right.$ and $\mathrm{b}=9.865$, $p<.001)$, lower total satisfaction damage $\left(\mathrm{SAT}_{\mathrm{A}}: \mathrm{b}=\right.$ $-1.621, p<.001$ and $\mathrm{b}=-.877, p<.10$ ), and restore satisfaction at higher levels 60 days after the recall $\left(\mathrm{SAT}_{60}: \mathrm{b}=-.027\right.$, $p<.01$ and $\mathrm{b}=-.024, p>.10$ ). Overall, we find support for H1.

Remedy*Brand Equity^2 H2 (+) H2 suggests that brand equity moderates the effect of remedy on satisfaction nonlinearly (u-shape), such that offering full (vs. partial) remedy

\footnotetext{
${ }^{2}$ Expected signs of coeffcients are reversed for $\mathrm{T}_{\text {rec}}$.
} 
mitigates the negative effect of the recall on satisfaction more for low and high brand equity firms than for medium brand equity firms. We only find support for one of the four metrics $\left(\mathrm{SAT}_{\mathrm{rec}}: \mathrm{b}=-4.041, p<.001\right)$, indicating that full remedy leads to a disproportionally shorter recovery time for low brand equity firms (see left chart for the metric $\mathrm{T}_{\text {rec }}$ in Fig. 2 ). The other three metrics are in the expected direction but not significant $\left(\mathrm{SAT}_{\min }: \mathrm{b}=.008, \mathrm{SAT}_{\mathrm{A}}: \mathrm{b}=0.324, \mathrm{SAT}_{60}\right.$ : $\mathrm{b}=.004$, all $p \mathrm{~s}>.10$ ). Overall, we find partial evidence for $\mathrm{H} 2$.

Severity*Remedy*Brand Equity H3a (+) In line with H3a, we find that severity moderates the negative linear interactive effect of remedy and brand equity on satisfaction positively (i.e., weaker linear interaction). Table 3 shows that all four satisfaction metrics are significant in both the linear and non-linear model. Specifically, we find that when severity is high (low), offering full remedy mitigates the negative effect of the recall on the largest satisfaction drop $\left(\mathrm{SAT}_{\min }: \mathrm{b}=\right.$ $-.051, p<.001$ and $\mathrm{b}=.053, p<.05)$, satisfaction recovery time ( $\mathrm{SAT}_{\text {rec }}: \mathrm{b}=-32.21, p<.001$ and $\mathrm{b}=-36.27, p<.001$ ), total satisfaction damage $\left(\mathrm{SAT}_{\mathrm{A}}: \mathrm{b}=4.560, p<.001\right.$ and $\mathrm{b}=$ $4.416, p<.001$ ), and satisfaction level 60 days post-recall $\left(\mathrm{SAT}_{60}: \mathrm{b}=.227, p<.001\right.$ and $\left.\mathrm{b}=.173, p<.10\right)$ less (more) for firms with lower brand equity than for firms with higher brand equity. Overall, we find support for H3a.

Severity*Remedy*Brand Equity^2 H3b (+) In line with H3b, we find that severity moderates the non-linear interactive effect of remedy and brand equity on satisfaction positively (i.e., stronger non-linear interaction and more pronounced $\mathrm{u}$ shape). Table 3 shows that the three-way interaction effect Severity*Remed ${ }^{*}$ Brand Equity 2 is significantly different from zero for all four satisfaction metrics. When severity is high (low) offering full remedy mitigates the negative effect of the recall on the largest satisfaction drop $\left(\mathrm{SAT}_{\min }: \mathrm{b}=.034\right.$, $p<.05)$, satisfaction recovery time $\left(\mathrm{SAT}_{\text {rec }}: \mathrm{b}=-15.90\right.$, $p<.001)$, total satisfaction damage $\left(\mathrm{SAT}_{\mathrm{A}}: \mathrm{b}=2.795\right.$, $p<.001$ ), and satisfaction level 60 days after the recall $\left(\mathrm{SAT}_{60}: \mathrm{b}=.125, p<.001\right)$ more (less) for low and high brand equity firms than for medium brand equity firms. Figure 2 illustrates the complex non-linear interaction effect between severity, remedy, and brand equity on satisfaction recovery: the charts in the right column of Fig. 2 show how low and high brand equity firms can restore satisfaction much better when offering full remedy. Web Appendix E augments the visualization of Fig. 2 with a spotlight analysis.

Robustness checks Web Appendix F shows the results for an alternative model specification using Kernel matching and a simultaneously estimated four-equation linear regression model. Although this alternative specification is inferior compared to the quantile regression, the findings are generally in line with the quantile regression results. Overall, we find support for $\mathrm{H} 1, \mathrm{H} 3 \mathrm{a}$, and $\mathrm{H} 3 \mathrm{~b}$ but not for $\mathrm{H} 2$.

\section{Discussion}

Study 1 provides a longer-term perspective on the impact of a product recall on satisfaction recovery and showcases managerially relevant metrics to illustrate the post-recall customer satisfaction trajectory. An analysis of real-world recall events reveals that when severity is low, full remedy only has a more positive impact on satisfaction recovery than partial remedy when brand equity is low, whereas high brand equity firms can afford to offer partial remedy. When severity is high, full remedy is more beneficial compared to partial remedy for low and high brand equity firms. These findings suggest that firms need to consider failure severity and brand equity when they decide on the appropriate remedy to manage customer satisfaction. Importantly, the observed changes in satisfaction are also likely to impact firms' bottom line: A post-analysis using YouGov's purchase intent metric shows a meaningful correlation with the satisfaction metric $(r=.26, \mathrm{p}<.001){ }^{3}$ However, the field study has limitations with regard to internal validity because firms' remedy offer might also depend on other, unobserved factors. To address this limitation, Study 2 randomizes remedy offer and studies the subsequent change in satisfaction, conditional on pre-recall brand equity.

\section{Study 2: The joint influence of remedy and brand equity on satisfaction}

\section{Participants, method and design}

Five-hundred and fifty-three US-based participants $\left(\mathrm{M}_{\mathrm{age}}=38.98,57 \%\right.$ female $)$ with an approval rating of $95 \%$ or higher completed this online survey for a small payment through the TurkPrime application (Litman, Robinson and Abberbock 2017). We employed a single factor (remedy: partial vs. full) between-subjects design with random assignment.

Participants first selected their current smartphone brand and we assessed their respective pre-recall satisfaction (three items from the American Customer Satisfaction Index; sample item: "To what extent does X's product meet your expectations?", $1=$ falls short of expectations, $7=$ exceeds expectations, $\alpha=.86, \mathrm{AVE}=78.83 \%$ ) and brand equity (five-item scale from Brady et al. 2008; sample item: "How would you rate the quality delivered by (BRAND)?", $1=$ low, $7=$ high, $\alpha=.88, \mathrm{AVE}=70.22 \%$; see Web Appendix G for an

\footnotetext{
${ }^{3}$ YouGov added the indicator Purchase Intent at the end of 2012 to the BrandIndex. This metric is therefore only available for a subset of 119 recall events, inhibiting us to include it in the formal model.
} 


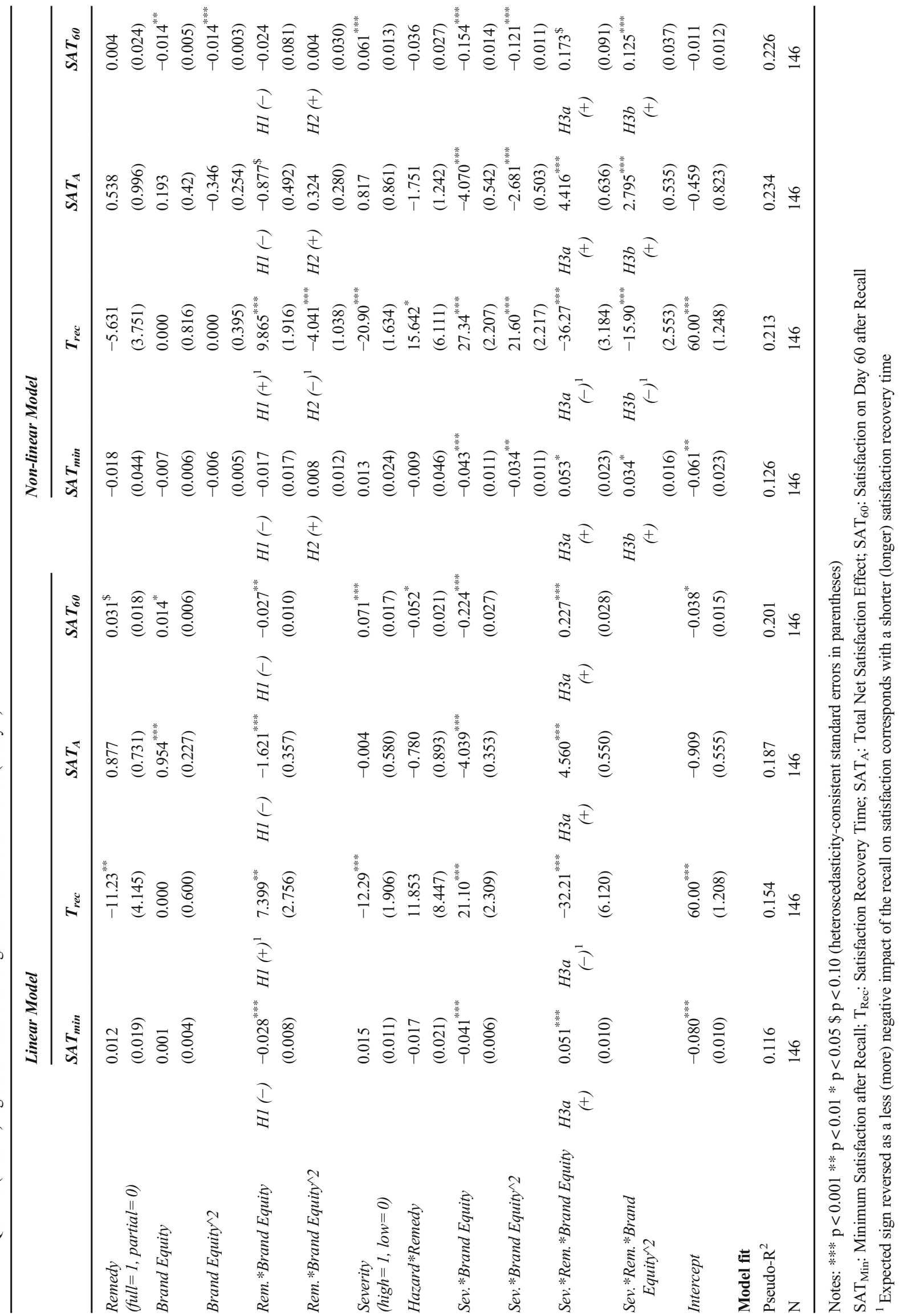




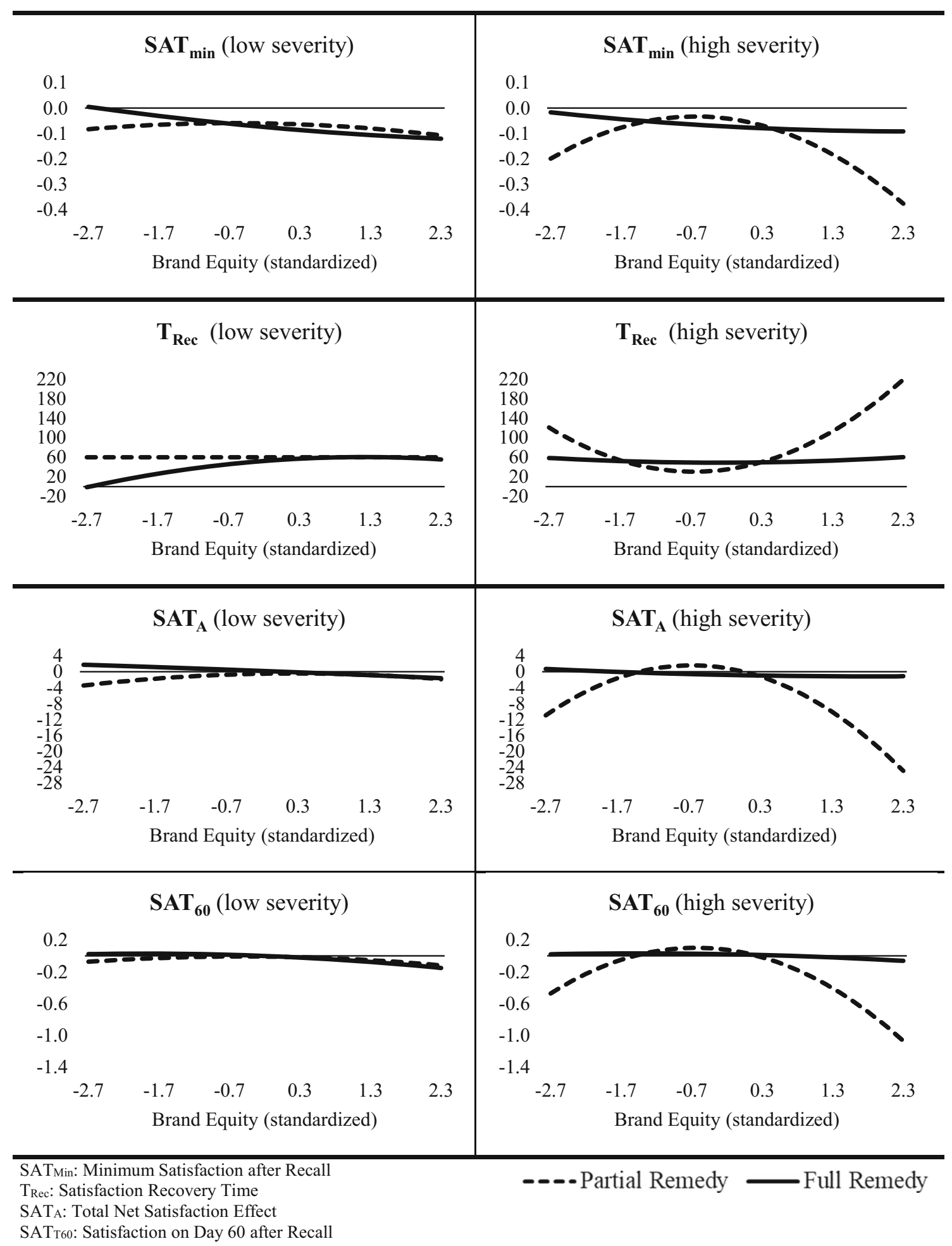

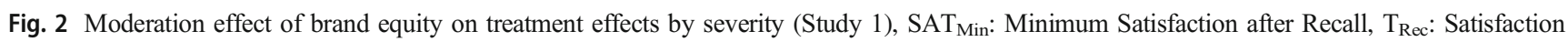
Recovery Time, $\mathrm{SAT}_{\mathrm{A}}$ : Total Net Satisfaction Effect, $\mathrm{SAT}_{\mathrm{T} 60}$ : Satisfaction on Day 60 after Recall

overview of all measurement constructs, manipulation checks, and attention checks). We measured, rather than manipulated, brand equity because it relies on brand associations that are formed over time (Keller 1993). Next, they were exposed to a recall announcement supposedly issued by the CPSC. The recall stated that irregularly positioned wires close to the battery can lead to explosions, posing a fire and burn hazard to consumers. The recall announcement reflects a high severity recall, consistent with high severity events in Study 1. Participants were informed that the firm offered either partial 
(free do-it-yourself repair kit) or full remedy (free inspection and full repair, see Web Appendix $\mathrm{H}$ for details).

After that, we assessed post-recall satisfaction using the same three items as for pre-recall satisfaction, but added "After reading details about the recall..." before each item $(\alpha=.95, \mathrm{AVE}=90.77 \%)$, to calculate our dependent variable relative change in satisfaction $(\Delta$ Satisfaction $=\ln ($ Post-recall Satisfaction + 1)/ $\ln ($ Pre-recall Satisfaction + 1)-1).

As manipulation check, we asked participants what remedy the firm offered according to the official recall announcement by the CPSC (arrange for free inspection and full repair vs. send a free do-it-yourself repair kit). We also assessed perceived failure severity ( $1=$ not severe at all, $7=$ very severe), smartphone expertise (three items from Thompson et al. 2005; sample item: "Relative to others, I know a lot about smartphones," $1=$ totally disagree, $7=$ totally agree, $\alpha=.92$, $\mathrm{AVE}=86.83 \%$ ), if they ever repaired their own smartphone (yes, no), how comfortable they would be to repair their smartphone ( $1=$ not at all, $7=$ very $)$, the smartphone's price (USD) and age (months), and participants' age and gender. Finally, we debriefed participants and told them that the recall announcement was fictional and that no recall had occurred.

\section{Results}

Group equivalence Participants in both groups did not differ regarding pre-recall brand equity, pre-recall satisfaction, severity, age, gender, phone brand, age and price of the phone, or familiarity with smartphones (p's $>0.10$ ), see Table I1 in Web Appendix I for more details).

Manipulation check The majority of participants in the partial $(93.4 \%)$ and full $(97.8 \%)$ remedy condition identified the offered remedy correctly $\left(\beta=-1.16, S E=.48, \chi^{2}=5.89\right.$, $p=.015)$, providing evidence that the manipulation check was successful. Further, participants perceived the recall as severe $\left(\mathrm{M}_{\text {Severity }}=5.07, \mathrm{SD}=1.57\right.$, significantly higher than the scale midpoint $(\mathrm{t}(1,552)=16.07, p<.001)$.

Empirical strategy Table I 2 in Web Appendix I shows the descriptive statistics and correlations of model variables. The descriptive analysis shows that the satisfaction metric has a heavy tail distribution and unbalanced outliers (see Fig. I1 in Web Appendix I). Further, the outcome variance differs between treatment groups $(p<0.001$, see Table I3 in Web Appendix I). We therefore apply the same methodology as in Study 1 and estimate a quantile (median) regression model. Participants in the full (vs. partial) remedy condition reported a smaller drop in satisfaction $\left(\mathrm{M}_{\text {full }}=-0.023\right.$ vs. $\mathrm{M}_{\text {partial }}=$ $\left.-0.079 ; \mathrm{b}_{\text {Rem }}=0.056, \mathrm{SE}=0.012, \mathrm{p}<0.001\right)$. Table 4 provides a summary of the regression results when we add the linear and quadratic terms of brand equity and the interaction effects with remedy.
Remedy*brand equity H1 (-) The impact of remedy on satisfaction is negatively moderated by brand equity, such that the effect of full (partial) remedy on satisfaction is more (less) positive for low compared to high brand equity firms (linear model: $\mathrm{b}_{\mathrm{Rem} * \mathrm{BE}}=-0.029, p<0.05$, non-linear model: $\left.\mathrm{b}_{\mathrm{Rem} * \mathrm{BE}}=-0.030, p<0.01\right)$, supporting H1. Figure 3 shows that the gap between full and partial remedy increases with decreasing brand equity.

Remedy*brand equity^ $2 \mathrm{H} 2(+) \mathrm{H} 2$ predicts that full remedy is relatively more important for low and high versus medium brand equity firms. The interaction effect Remedy*Brand Equity $^{\wedge} 2$ is indeed significantly positive $\left(b_{\operatorname{Rem}^{*} \mathrm{BE}^{\wedge} 2}=0.008\right.$, $\mathrm{p}<0.05$ ), supporting H2. Figure 3 shows a u-shape for the full effect of remedy on satisfaction over the brand equity bandwidth. The effect of full remedy on satisfaction is weakest for medium brand equity firms. The conditional effect analysis in Table I4 (Web Appendix I) shows that the satisfaction level does not change for very low and very high brand equity firms if they offer full remedy $\left(\mathrm{M}_{\text {full } \& \mathrm{BE}=\min }=-0.031\right.$, $\mathrm{CI}_{95 \%}=[-0.074 ; 0.011] ; \mathrm{M}_{\text {fu11 \& } \mathrm{BE}=\max }=0.000$, $\left.\mathrm{CI}_{95 \%}=[-0.008 ; 0.008]\right)$. In particular, the effect for very high brand equity firms offering full remedy is significantly different from the effect for medium brand equity firms because both confidence intervals do not overlap $\left(\mathrm{CI}_{95 \%}\right.$ (full, $\left.\mathrm{BE}_{\max }\right)=[-0.008 ; 0.008]$ vs. $\mathrm{CI}_{95 \%}\left(\right.$ full, $\left.\mathrm{BE}_{\text {mean }}\right)=[-0.051$; $-0.014])$.

Robustness checks The interactive effect of Remedy*Brand Equity is especially relevant if customers show an average change in satisfaction. In case of extremes, i.e., very small (e.g., 10\% quantile) or very large (e.g., 90\% quantile) satisfaction changes the Remedy*Brand Equity interactions become insignificant (see Table I5 in Web Appendix I). To further rule out the effect of outliers, Table I6 in Web Appendix I presents the results of an outlier robust regression analysis. The effects replicate. Taken together, we find evidence in support of $\mathrm{H} 1$ and $\mathrm{H} 2$.

\section{Discussion}

Study 2 shows that remedy and brand equity have a joint impact on satisfaction in the short-term. While offering full remedy is the dominant strategy, the results highlight that offering full remedy is particularly important for low and high brand equity firms. These firms can preserve satisfaction at the pre-recall level whereas medium brand equity firms experience a satisfaction decline regardless of remedy offer. The gap between full and partial remedy follows a non-linear pattern, where low brand equity firms experience a disproportionally steeper decline in satisfaction when they offer partial remedy. While these results provide further evidence supporting our hypotheses, the scenario featured in Study 2 corresponds to a 
Table 4 Quantile (median) regression results for Study 2

Dependent Variable: Change in Satisfaction

\begin{tabular}{|c|c|c|c|c|c|c|}
\hline \multirow{3}{*}{ Independent variables } & & & & & & \\
\hline & & \multicolumn{3}{|c|}{ Linear Model } & \multicolumn{2}{|c|}{ Non-linear Model } \\
\hline & & Coef. & $\mathbf{S E}^{\mathbf{a}}$ & & Coef. & $\mathbf{S E}^{\mathbf{a}}$ \\
\hline Remedy (full vs partial) & & $0.066^{* * *}$ & 0.014 & & $0.062^{* * * *}$ & 0.014 \\
\hline Brand Equity (mean centered) & & $0.081^{* * * *}$ & 0.017 & & $0.077^{* * * * *}$ & 0.020 \\
\hline Brand Equity^2 & & & & & $-0.012^{*}$ & 0.006 \\
\hline Remedy*Brand Equity & $H 1(-)$ & $-0.029^{*}$ & 0.013 & $H 1(-)$ & $-0.030^{* *}$ & 0.011 \\
\hline Remedy*Brand Equity^2 & & & & $H 2(+)$ & $0.008^{*}$ & 0.004 \\
\hline Intercept & & $-0.164^{* * * *}$ & 0.019 & & $-0.157^{* * * *}$ & 0.022 \\
\hline \multicolumn{7}{|l|}{ Model Fit } \\
\hline Pseudo- $\mathrm{R}^{2}$ & & 0.073 & & & 0.076 & \\
\hline $\mathrm{N}$ & & 553 & & & 553 & \\
\hline
\end{tabular}

Notes: $* * * p<0.001 * * p<0.01 * p<0.05 \$ p<0.10$

${ }^{a}$ heteroscedasticity-consistent standard errors

high severity failure (based on high severity recalls from Study 1). To provide further evidence of the role of severity as a boundary condition of the interactive effect between remedy and brand equity we therefore present a second experiment where we manipulate both remedy and severity.

\section{Study 3: The moderating influence of failure severity}

\section{Participants, method and design}

Seven-hundred and twenty-four US-based participants $\left(\mathrm{M}_{\mathrm{age}}=\right.$ $36.01,53 \%$ female) with an approval rating of $95 \%$ or higher completed this study for a small payment through TurkPrime. We employed a between-subjects design with brand equity as a

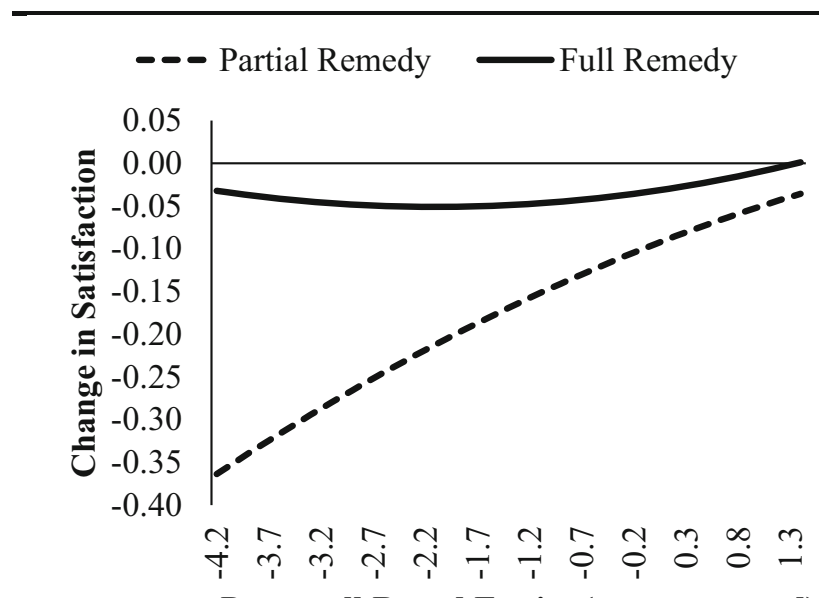

Pre-recall Brand Equity (mean centered)

Fig. 3 Plot of non-linear remedy * brand equity interaction (Study 2) measured continuous variable and severity (low vs. high) and remedy (partial vs. full) as manipulated factors.

To provide evidence that our effects generalize across products, participants where now asked to indicate their current laptop brand and we assessed their respective brand equity $(\alpha=.89$, $\mathrm{AVE}=71.82 \%)$. Next, respondents were told that their laptop brand recently had to recall certain laptops for safety issues. On the next screen, they were exposed to a recall announcement supposedly issued by the CPSC in cooperation with their brand. The structure and content of the recall announcement was identical to those released by the CPSC, see Web Appendix J for details. We manipulated severity by modifying both hazard (high severity: explosions, thereby posing a fire and burn hazard to consumers; low severity: overheating, thereby leading only to permanent damage to the laptop) and incidents reported (high severity: 47 reports of burns and injuries or damage to property; low severity: no reports of injuries or damage to property). Thus, the severity manipulation entails information about different degrees of potential (hazard) and actual (incidents) danger to consumers (Germann et al. 2014). In order to manipulate remedy, the announcement stated that the laptop brand either offered full (free inspection and full repair) or partial remedy (free do-it-yourself repair kit), similar to Study 2. After reading details about the recall, participants indicated their satisfaction with the laptop brand on the same set of items as in Study $2(\alpha=.91$, AVE $=85.29 \%$ ). Next, we assessed perceived severity ("Based on this information, how severe would you rate this product recall?", $1=$ not severe at all, $7=$ very severe"). Participants also indicated their expertise regarding laptops using the same scale as in Study $2(\alpha=.92$, 
AVE $=85.98 \%$ ), the laptop's price (USD), and the laptop's age (months), among others. Finally, respondents were again debriefed.

\section{Results}

Group equivalence Participants in all conditions did not differ regarding pre-recall brand equity, gender, laptop brand, age and price of the laptop (p's $>0.05$, see Table K1 in Web Appendix $\mathrm{K}$ for more details). Results do not change when including these variables as controls.

Manipulation check Participants perceived the high severity condition as more severe $\left(\mathrm{M}_{\text {High }}=5.65, \mathrm{SD}=1.28\right.$ vs. $\mathrm{M}_{\text {Low }}=4.39, \mathrm{SD}=1.48, \mathrm{~F}(1,723)=151.09, p<.001$, $d=.91)$. Further, the interaction between remedy and severity did not significantly affect the severity measure, signaling that the severity manipulation worked independently from the remedy manipulation $(\mathrm{F}(1,723)=2.52, p=.12)$.

Empirical strategy Table K2 in Web Appendix K displays the descriptive statistics and correlations of model variables. Fig. $\mathrm{K} 1$ in Web Appendix K shows that the satisfaction metric has a heavy tail distribution but, unlike in Study 2, does not show any outliers. Although the outcome shows unequal variances between treatment groups ( $p<0.001$, see Table K3 in Web Appendix I), the variance ratios are smaller compared to Study 2. We therefore estimate a mean regression model. Table 5 shows the results for the linear and non-linear model and Fig. 4 visualizes the non-linear three-way interaction effect.

Remedy*brand equity $\mathrm{H} 1$ (-) This study replicates the negative Remedy*Brand Equity interaction effect (linear model: $\mathrm{b}_{\text {Rem*BE}}=-0.243, p<0.05$, non-linear model: $\mathrm{b}_{\text {Rem*BE}}=$ $-0.273, \mathrm{p}<0.001)$ from Study 1. Low brand equity firms preserve satisfaction better if they offer full remedy. For high brand equity firms, the remedy offer is less relevant, providing support for $\mathrm{H} 1$.

Remedy*brand equity^2 $\mathrm{H} 2$ (-) We do not find a significant Remedy $*$ Brand Equity 2 interaction effect $\left(\mathrm{b}_{\mathrm{Rem} * \mathrm{BE}^{\wedge} 2}=\right.$ $-0.053, p>0.10)$. $\mathrm{H} 2$ is not supported.

Severity*remedy*brand equity $\mathrm{H} 3 \mathrm{a}(+)$ We predict that the negative interaction effect Remed ${ }^{*}$ Brand Equity becomes weaker (stronger) when severity is high (low). In line with this hypothesis, and replicating the results from the two previous studies, full remedy becomes more important for satisfaction for high brand equity firms when severity is high (linear model: $\mathrm{b}_{\mathrm{Sev} * \mathrm{Rem} * \mathrm{BE}}=0.366, \mathrm{p}<0.001$, non-linear model: $\mathrm{b}_{\mathrm{Sev} * \mathrm{Rem} * \mathrm{BE}}=$ $0.435, p<0.001)$. Figure 4 visualizes this effect. When severity is low, the gap between full and partial remedy narrows with increasing brand equity while this effect is not present when severity is high, providing support for $\mathrm{H} 3 \mathrm{a}$.

Severity*remedy*brand equity^2 H3b (+) This gap between partial and full remedy becomes disproportionally larger if brand equity is high and if failure severity is high. Replicating Study 1 and 2, we find this predicted non-linear three-way interaction effect Severity*Remed ${ }^{*}$ Brand Equity ${ }^{\wedge}\left(\mathrm{b}_{\mathrm{Sev}^{*} \mathrm{Rem}^{*} \mathrm{BE}^{\wedge} 2}=0.100, p<0.10\right)$. The spotlight analysis in Table K4 in Web Appendix K shows that when severity is low, full remedy significantly improves satisfaction compared to partial remedy for most firms. However, the positive effect of offering full remedy becomes weaker with increasing brand equity level. At very high brand equity levels, the full remedy effect disappears. However, when severity is high, very high brand equity firms can preserve satisfaction only when they offer full remedy. Similar to Studies 1 and 2 we find directional support that the effect of full remedy on satisfaction increases also at the lower end of the brand equity continuum. Yet, in Study 3, this effect is not significantly different from zero. In line with the field study, we find support for $\mathrm{H} 1, \mathrm{H} 3 \mathrm{a}$, and $\mathrm{H} 3 \mathrm{~b}$, but not for $\mathrm{H} 2$.

\section{Discussion}

Study 3 systematically tests the moderating impact of severity on the interactive effect of brand equity and remedy on satisfaction. The results replicate the main findings of Studies 1 and 2. That is, when severity is low, choosing full remedy instead of partial remedy restores satisfaction more with decreasing levels of brand equity, providing an opportunity for low brand equity firms. In this situation, high brand equity firms can benefit from a buffer effect which allows them to offer partial remedy. However, when failure severity is high, this pattern changes: Full remedy is better able to preserve and restore satisfaction for high brand equity firms. In contrast to Study 1 and 2, we do not find this effect at the lower end of the brand equity continuum, potentially due to the smaller number of very low (compared to very high) brand equity cases.

\section{General discussion}

What remedy should a firm offer to restore satisfaction after a product recall? Should the firm's brand equity level influence this decision? How do recall characteristics, such as failure severity, influence customers' response to the recall? The existing literature on product recalls lacks empirically based answers to these important questions. We provide these answers and thereby contribute to the literature on satisfaction management after a product recall, providing managers with guidelines to make informed remedy choices. 
Table 5 Mean regression results for Study 3

\begin{tabular}{|c|c|c|c|c|c|c|}
\hline \multirow[b]{3}{*}{ Independent variables } & & \multicolumn{5}{|c|}{ Dependent Variable: Post-recall Satisfaction } \\
\hline & & \multicolumn{3}{|c|}{ Linear Model } & \multicolumn{2}{|c|}{ Non-linear Model } \\
\hline & & Coef. & $\mathbf{S E}^{\mathbf{a}}$ & & Coef. & $\mathbf{S E}^{\mathbf{a}}$ \\
\hline Remedy (full vs. partial) & & $0.618^{* * * *}$ & 0.054 & & $0.688^{* * * *}$ & 0.094 \\
\hline Brand Equity (mean cantered) & & $0.830^{* * * *}$ & 0.071 & & $0.827^{* * *}$ & 0.080 \\
\hline Brand Equity^2 & & & & & -0.004 & 0.028 \\
\hline Remedy*Brand Equity & $H 1(-)$ & $-0.243^{*}$ & 0.087 & $H 1(-)$ & $-0.273^{* * *}$ & 0.061 \\
\hline Remedy*Brand Equity^2 & & & & $H 2(+)$ & -0.053 & 0.038 \\
\hline Severity & & -0.093 & 0.113 & & 0.005 & 0.125 \\
\hline Severity*Remedy (full vs. partial) & & $-0.338^{* *}$ & 0.112 & & $-0.477^{* *}$ & 0.127 \\
\hline Severity*Brand Equity & & $-0.167^{*}$ & 0.073 & & $-0.221^{*}$ & 0.081 \\
\hline Severity*Brand Equity 2 & & & & & -0.069 & 0.057 \\
\hline Severity*Remedy*Brand Equity & $H 3 a(+)$ & $0.366^{* *}$ & 0.120 & $H 3 a(+)$ & $0.435^{* * *}$ & 0.097 \\
\hline Severity*Remedy*Brand Equity^2 & & & & $H 3 b(+)$ & $0.100^{\$}$ & 0.056 \\
\hline Intercept & & $4.681^{* * *}$ & 0.087 & & $4.687^{* * * *}$ & 0.080 \\
\hline \multicolumn{7}{|l|}{ Model Fit } \\
\hline F-value & & 636.010 & & & 1280.240 & \\
\hline $\mathrm{R}^{2}$ & & 0.400 & & & 0.403 & \\
\hline $\mathrm{N}$ & & 724 & & & 724 & \\
\hline
\end{tabular}

Notes: $* * * \mathrm{p}<0.001 * * \mathrm{p}<0.01 * \mathrm{p}<0.05 \$ \mathrm{p}<0.10$

${ }^{a}$ heteroscedasticity-consistent standard errors

\section{Theoretical implications}

First and foremost, restoring relational imbalance after a negative event is crucial to sustaining firm success (Grégoire and Fisher 2006; Hess, Ganesan and Klein 2003). However, the existing literature on product recalls largely neglects the role of compensation (Cleeren et al. 2017), even though other related streams of literature provide evidence that compensation is crucial for satisfaction recovery (Gelbrich and Roschk 2011). We draw on reactive equity theory and the
Fig. 4 Moderation effect of brand equity on treatment effects by severity (Study 3 )

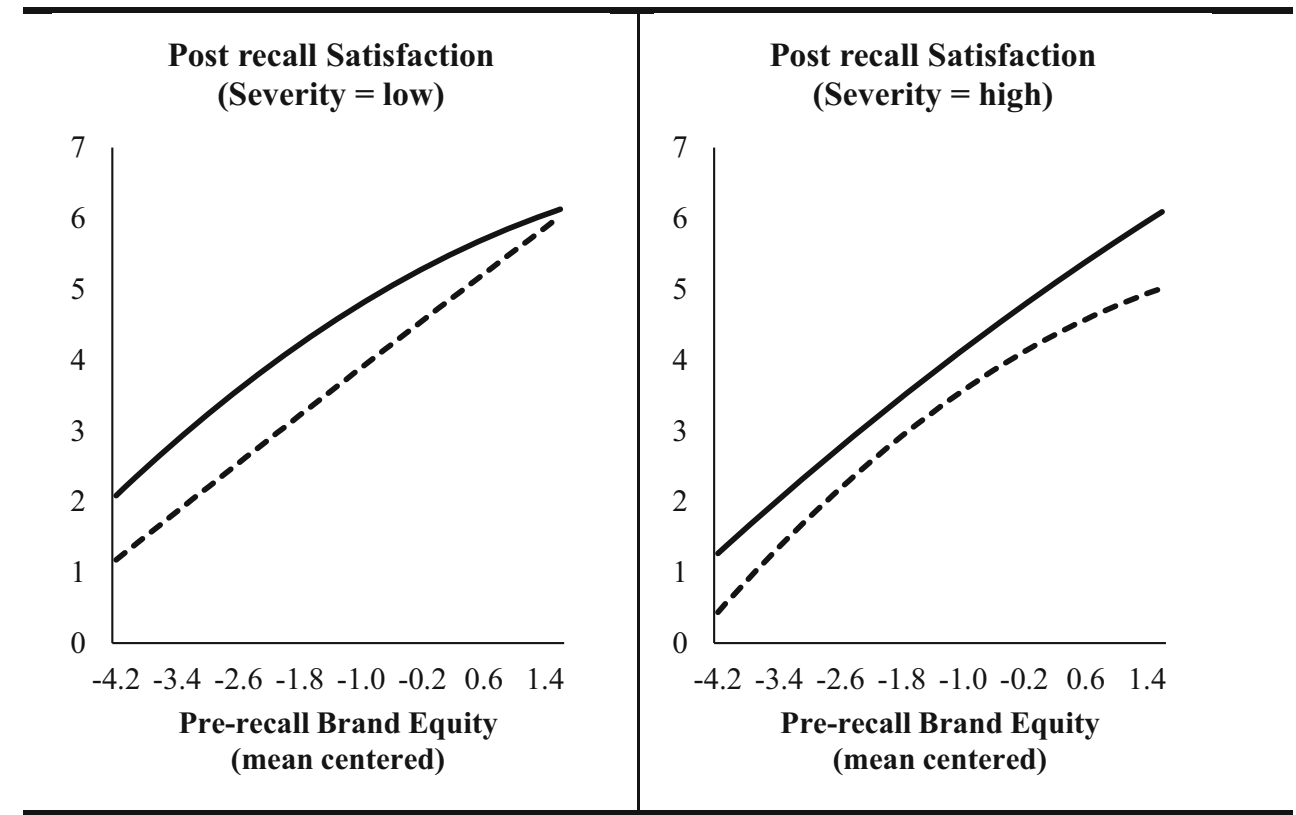

- - - Partial Remedy —-Full Remedy 
expectation-disconfirmation framework and offer an integrative framework to shed light on the joint influence of remedy choice, brand equity, and severity on satisfaction.

Second, we offer an internally valid perspective of remedy choice on satisfaction (Study 2 and 3 ) and also provide externally valid longer-term insights (Study 1). An analysis of four different satisfaction metrics reveals that both low and high brand equity firms can recover satisfaction more quickly, limit the total damage to their satisfaction, and avoid large drops in satisfaction after the recall if they offer full remedy. To the best of our knowledge, this is the first study to offer such a holistic picture on customer satisfaction recovery after a product recall.

Third, we extend the literature on the influence of recall characteristics on customers' response to a recall and the corresponding firm behavior (Gao et al. 2015; Germann et al. 2014). Studies 1 and 3 suggest that the severity of the failure changes the influence of remedy on satisfaction for both, low, and high brand equity firms. More specifically, including severity as a boundary condition reveals situations where different firms can choose to offer partial remedy (i.e., the inferior and cheaper option) and when it is crucial to offer full remedy (i.e., the superior and costlier option) to prevent further damage to satisfaction.

\section{Managerial implications}

As Cleeren et al. (2017: 610) note, "a single best strategy (for firms) may be to try to avoid product-harm crises. "However, the increasing complexity of global supply chains makes it nearly impossible for firms to avoid the occurrence of product recalls, and when those unfortunate events occur, firms are naturally concerned about brand equity and satisfaction. Surprisingly, work on those two intangible assets proceeds largely separately in most firms. Our research shows that managers need to have a clear understanding of how remedy and brand equity jointly influence satisfaction before deciding which remedy they should offer. Intuitively, one might suggest that firms should always offer full remedy to reestablish relational balance, yet, we suggest that this further depends on how severe the failure is. Figure 5 illustrates the 5R guidelines (Reap, Realize, Repel, Rely, Revoke) which summarize the implications of our findings for managerial decision making.

When firms respond to a product recall, they need to balance short-term (financial costs of the recall) and long-term non-financial (satisfaction) and financial consequences. Although saving costs is tempting in the short term, the company's relationship with its customers may be threatened in the long term. We investigate the interactive effect of brand equity and remedy on satisfaction and expand the emerging evidence that brand equity does not always serve as a buffer.
Our results suggest that firms should consider the following four important effects.

High brand equity firms: Reap the buffering effect and repel the boomerang effect Consumer response studies support a buffer effect of high brand equity: By offering partial remedy, high brand equity firms control their losses in terms of customer satisfaction (Dawar and Pillutla 2000; Dean 2004; Erdem and Swait 1998; Hess 2008) as well as financial performance (partial remedy is cheaper; Liu et al. 2016). Yet, this buffering effect only occurs when severity is low. In contrast, when severity is high, high brand equity firms need to offer full remedy to confirm to customers' high standards. This corresponds with research showing that highly committed consumers may react more negatively to a crisis when the crisis is severe (Germann et al. 2014). Here, offering only partial remedy backfires and leads to a boomerang effect. Importantly, these effects are even more pronounced for firms with very high brand equity.

Medium brand equity firms: Rely on the ambivalence effect Due to customers' ambivalent experiences with, and expectations towards medium brand equity firms, both buffering and boomerang effects are weaker compared to high brand equity firms. In comparison to low brand equity firms, medium brand equity firms are less likely to receive outright disapproval by choosing partial remedy when severity is high. We find evidence for this argument. While customer satisfaction is slightly higher when these firms offer full remedy, they neither benefit, nor are they penalized, to the same extent as low and high brand equity firms when they offer only partial remedy. In turn, this also means that these firms have little strategic leverage to influence customer satisfaction significantly through their remedy offer.

Low brand equity firms: Realize the opportunity and revoke the wipe-out effect Firms with low brand equity cannot rely on their reputation to buffer negative consequences from a product recall to the same extent. However, there are situations where these firms can benefit from making the 'right' remedy choice, but also situations where their existence is threatened by making the 'wrong' remedy choice. Specifically, our findings identify an opportunity for low brand equity firms to shorten their satisfaction recovery time significantly if they offer full remedy. In addition, they are able to limit the satisfaction loss after the recall disproportionally more than high brand equity firms. These positive effects of offering full remedy are especially pronounced when severity is low. When severity is high, our results underscore the importance for low brand equity firms to offer full remedy in order to prevent a wipe-out effect. As these firms cannot rely on their reputation to buffer some of 
Fig. 5 The $5 \mathrm{R}$ guidelines for optimal remedy choice after a product recall

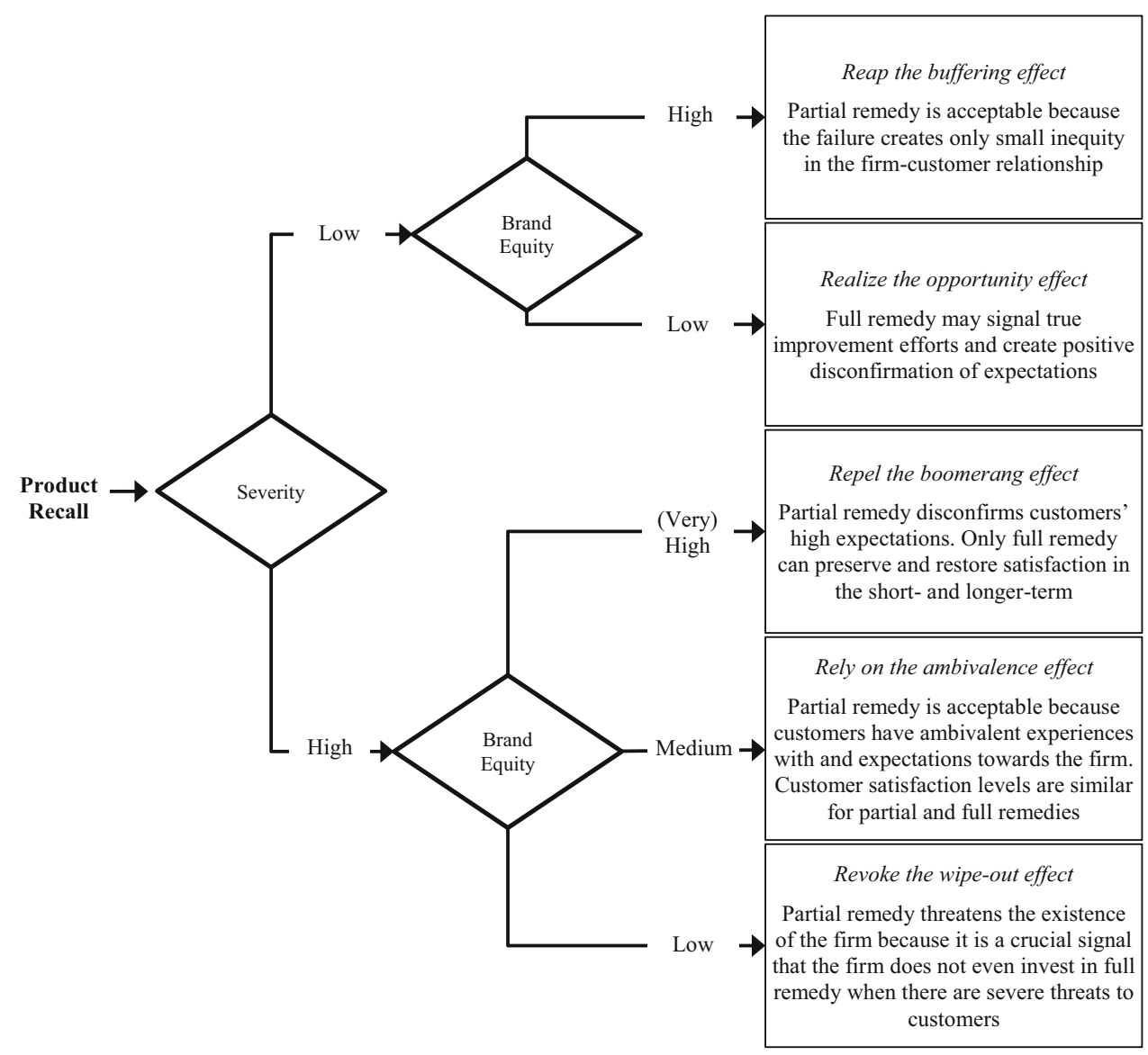

the negative consequences of the recall, only offering partial remedy exacerbates these negative effects. Importantly, these findings are most relevant for those firms with very low brand equity.

Our results also have implications for the interface between brand management and customer relationship management. In particular, we suggest that marketing managers should put more pressure on the finance department, which has strong incentives to opt for the cheaper (partial) remedy. Instead, they should consider offering full remedy to protect the long-term relationship with customers and subsequent financial success. Making these choices will lead to a trade-off: Full remedy is more costly than partial remedy (Liu et al. 2016) but at the same time, full remedies help firms to recover customer satisfaction after the recall, thereby positively influencing sales (Bernhardt, Donthu and Kennett 2000) and shareholder value (Anderson, Fornell and Mazvancheryl 2004). Moreover, offering full remedy might help in protecting firm value, as the firm value elasticity of customerrelated assets, such as satisfaction, is .72 (Edeling and Fischer 2016). Considering, and quantifying, these trade-offs will help firms to build more nuanced models when forecasting the impact of remedy decisions. In the field study, we develop four insightful metrics that can help managers monitor, control, and evaluate the recovery of satisfaction following the recall.

\section{Limitations and future research opportunities}

First, the conceptualization of remedy used in this study is based on the established classification into full and partial remedy (e.g., Liu et al. 2016; Raithel and Hock 2020). However, more fine-grained classifications, including a multifaceted taxonomy of different remedy types and their conformity with response options (e.g., Bundy and Pfarrer 2015; Dawar and Pillutla 2000), might provide additional insights into optimal recall management. Second, strategic considerations determine firms' decisions on remedy choice (e.g., personal incentives for managers; Liu et al. 2016). Future research should therefore examine the antecedents of firms' remedy decisions and their joint impact on customers' and financial market actors' responses (e.g., Raithel, Mafael and Hock 2021). Third, the current research lacks a deeper understanding of the cognitive and affective processes that underlie customers' assessment of and response to firms' behavior following crisis events (see Cleeren et al. 2017 and Khamitov et al. 2020 for reflections on this topic). Future research could focus on building a better understanding how different firms' actions are able to influence these processes, e.g., through their remedy offer. Fourth, it would be valuable to observe whether the effects described in this research differ between industries. We do not investigate such differences 
due to sample limitations and the overall complexity of the proposed effects. Further research using other dependent variables could develop guidelines specifically tailored to various industries. In summary, we believe that this research represents a holistic effort to understand the impact of firms' remedy choices on customer satisfaction recovery. Our findings open up the potential for further research in these and related areas.

Supplementary Information The online version contains supplementary material available at https://doi.org/10.1007/s11747-021-00802-1.

Funding Open access funding provided by Stockholm School of Economics.

Open Access This article is licensed under a Creative Commons Attribution 4.0 International License, which permits use, sharing, adaptation, distribution and reproduction in any medium or format, as long as you give appropriate credit to the original author(s) and the source, provide a link to the Creative Commons licence, and indicate if changes were made. The images or other third party material in this article are included in the article's Creative Commons licence, unless indicated otherwise in a credit line to the material. If material is not included in the article's Creative Commons licence and your intended use is not permitted by statutory regulation or exceeds the permitted use, you will need to obtain permission directly from the copyright holder. To view a copy of this licence, visit http://creativecommons.org/licenses/by/4.0/.

\section{References}

Ahluwalia, R., Burnkrant, R. E., \& Unnava, H. R. (2000). Consumer response to negative publicity: The moderating role of commitment. Journal of Marketing Research, 37(2), 203-214.

Anderson, E. W., Fornell, C., \& Mazvancheryl, S. K. (2004). Customer satisfaction and shareholder value. Journal of Marketing, 68(4), $172-185$.

Bernhardt, K. L., Donthu, N., \& Kennett, P. A. (2000). A longitudinal analysis of satisfaction and profitability. Journal of Business Research, 47(2), 161-171.

Bonifield, C., \& Cole, C. (2007). Affective responses to service failure: Anger, regret, and retaliatory versus conciliatory responses. Marketing Letters, 18(1), 85-99.

Borah, A., \& Tellis, G. J. (2016). Halo (spillover) effects in social media: Do product recalls of one brand hurt or help rival brands? Journal of Marketing Research, 53(2), 143-160.

Brady, M. K., Cronin, J. J., Fox, G. L., \& Roehm, M. L. (2008). Strategies to offset performance failures: The role of brand equity. Journal of Retailing, 84(2), 151-164.

Bundy, J., \& Pfarrer, M. D. (2015). A burden of responsibility: The role of social approval at the onset of a crisis. Academy of Management Review, 40(3), 345-369.

Bundy, J., Pfarrer, M. D., Short, C. E., \& Coombs, W. T. (2017). Crises and crisis management: Integration, interpretation, and research development. Journal of Management, 43(6), 476-501.

Chandon, P., Wansink, B., \& Laurent, G. (2000). A benefit congruency framework of sales promotion effectiveness. Journal of Marketing, 64(4), 65-81.

Cheah, E., Chan, W., \& Chieng, C. (2007). The corporate social responsibility of pharmaceutical product recalls: An empirical examination of U.S. and U.K. markets. Journal of Business Ethics, 76(4), 427449.

Chen, Y., Ganesan, S., \& Liu, Y. (2009). Does a firm's product-recall strategy affect its financial value? An examination of strategic alternatives during product-harm crises. Journal of Marketing, 73(6), 214-226.

Cleeren, K., Dekimpe, M. G., \& Helsen, K. (2008). Weathering productharm crises. Journal of the Academy of Marketing Science, 36(2), 262-270.

Cleeren, K., Dekimpe, M. G., \& van Heerde, H. J. (2017). Marketing research on product-harm crises: A review, managerial implications, and an agenda for future research. Journal of the Academy of Marketing Science, 45(5), 593-615.

Colicev, A., Malshe, A., Pauwels, K., \& O'Connor, P. (2018). Improving consumer mindset metrics and shareholder value through social media: The different roles of owned and earned media. Journal of Marketing, 82(1), 37-56.

Davis, D. F., Golicic, S. L., \& Boerstler, C. N. (2011). Benefits and challenges of conducting multiple methods research in marketing. Journal of the Academy of Marketing Science, 39(3), 467-479.

Dawar, N., \& Pillutla, M. M. (2000). Impact of product-harm crises on brand equity: The moderating role of consumer expectations. Journal of Marketing Research, 37(2), 215-226.

Dean, A. M. (2004). Rethinking customer expectations of service quality: Are call centers different? Journal of Services Marketing, 18(1), 6077.

De Matos, C. A., Henrique, J. L., \& Rossi, C. A. V. (2007). Service recovery paradox: A meta-analysis. Journal of Service Research, 10(1), 60-77.

Eccles, R. G., Newquist, S. C., \& Schatz, R. (2007). Reputation and its risks. Harvard Business Review, 85(2), 104-114.

Edeling, A., \& Fischer, M. (2016). Marketing's impact on firm value: Generalizations from a meta-analysis. Journal of Marketing Research, 53(4), 515-534.

Erdem, T., \& Swait, J. (1998). Brand equity as a signaling phenomenon. Journal of Consumer Psychology, 7(2), 131-157.

Fehr, E., \& Gächter, S. (2000). Fairness and retaliation: The economics of reciprocity. Journal of Economic Perspectives, 14(3), 159-181.

Fincham, F. D., Jackson, H., \& Beach, S. R. (2005). Transgression severity and forgiveness: Different moderators for objective and subjective severity. Journal of Social and Clinical Psychology, 24(6), 860-875.

Fornell, C., Johnson, M. D., Anderson, E. W., Cha, J., \& Bryant, B. E. (1996). The American customer satisfaction index: Nature, purpose, and findings. Journal of Marketing, 60(4), 7-18.

Fornell, C., Morgeson III, F. V., \& Hult, T. G. M. (2016). Stock returns on customer satisfaction do beat the market: Gauging the effect of a marketing intangible. Journal of Marketing, 80(5), 92-107.

Gao, H., Xie, J., Wang, Q., \& Wilbur, K. C. (2015). Should ad spending increase or decrease before a recall announcement? The marketingfinance interface in product-harm crisis management. Journal of Marketing, 79(5), 80-99.

Gelbrich, K., \& Roschk, H. (2011). A meta-analysis of organizational complaint handling and customer responses. Journal of Service Research, 14(1), 24-43.

Germann, F., Grewal, R., Ross Jr., W. T., \& Srivastava, R. K. (2014) Product recalls and the moderating role of brand commitment. Marketing Letters, 25(2), 179-191.

Grégoire, Y., \& Fisher, R. J. (2006). The effects of relationship quality on customer retaliation. Marketing Letters, 17(1), 31-46.

Grégoire, Y., \& Fisher, R. J. (2008). Customer betrayal and retaliation: When your best customers become your worst enemies. Journal of the Academy of Marketing Science, 36(2), 247-261.

Grégoire, Y., Tripp, T. M., \& Legoux, R. (2009). When customer love turns into lasting hate: The effects of relationship strength and time 
on customer revenge and avoidance. Journal of Marketing, 73(6), $18-32$.

Hamilton, R. (2016). Consumer-based strategy: Using multiple methods to generate consumer insights that inform strategy. Journal of the Academy of Marketing Science, 44(3), 281-285.

Harmeling, C., Palmatier, R., Houston, M. B., \& Arnold, M. J. (2015). Transformational relationship events. Journal of Marketing, 79(5), $39-62$.

Hess, R. L. (2008). The impact of firm reputation and failure severity on customers' responses to service failures. Journal of Services Marketing, 22(5), 385-398.

Hess, R. L., Ganesan, A., \& Klein, N. M. (2003). Service failure and recovery: The impact of relationship factors on customer satisfaction. Journal of the Academy of Marketing Science, 31(2), 127-145.

Hodrick, R. J., \& Prescott, E. C. (1997). Postwar U.S. business cycles: An empirical investigation. Journal of Money, Credit and Banking, 29(1), 1-16.

Homburg, C., Koschate, N., \& Hoyer, W. D. (2005). Do satisfied customers really pay more? A study of the relationship between customer satisfaction and willingness to pay. Journal of Marketing, 69(2), 84-96.

Ingram, R., Skinner, S. J., \& Taylor, V. A. (2005). Consumers' evaluation of unethical marketing behaviors: The role of customer commitment. Journal of Business Ethics, 62(3), 237-252.

Inman, J. J., Dyer, J. S., \& Jia, J. (1997). A generalized utility model of disappointment and regret effects on post-choice valuation. Marketing Science, 16(2), 97-111.

Keiningham, T. L., Morgeson III, F. V., Aksoy, L., \& Williams, L. (2014). Service failure severity, customer satisfaction, and market share: An examination of the airline industry. Journal of Service Research, 17(4), 415-431.

Keller, K. L. (1993). Conceptualizing, measuring, and managing customer-based brand equity. Journal of Marketing, 57(1), 1-22.

Keller, K. L. (2001). Building customer-based brand equity: A blueprint for creating strong brands. MSI working paper, 01/107.

Khamitov, M., Grégoire, Y., \& Suri, A. (2020). A systematic review of brand transgression, service failure recovery and product-harm crisis: Integration and guiding insights. Journal of the Academy of Marketing Science, 48(3), 519-542.

Koenker, R., \& Bassett, G. (1978). Regression quantiles. Econometrica, 46(1), 33-50.

Korkofingas, C., \& Ang, L. (2011). Product recall, brand equity, and future choice. Journal of Marketing Management, 27(9-10), 959975 .

Litman, L., Robinson, J., \& Abberbock, T. (2017). TurkPrime.com: A versatile crowdsourcing data acquisition platform for the behavioral sciences. Behavior Research Methods, 49(2), 433-442.

Liu, A., Liu, Y., \& Luo, T. (2016). What drives a firm's choice of product recall remedy? The impact of remedy cost, product hazard, and the CEO. Journal of Marketing, 80(3), 79-95.

Liu, Y., Shankar, V., \& Yun, W. (2017). Crisis management strategies and the long-term effects of product recalls on firm value. Journal of Marketing, 81(5), 30-48.

Loomes, G., \& Sugden, R. (1986). Disappointment and dynamic consistency in choice under uncertainty. The Review of Economic Studies, 53(2), 271-282.

Luo, X., Raithel, S., \& Wiles, M. A. (2013). The impact of brand rating dispersion on firm value. Journal of Marketing Research, 50(3), 399-415.

Malshe, A., Colicev, A., \& Mittal, V. (2020). How Main street Drives Wall street: Customer (dis) satisfaction, Short sellers, and abnormal returns. Journal of Marketing Research, 57(6), 1055-1075.

McCullough, M. A., Berry, L. L., \& Yadav, M. S. (2000). An empirical investigation of customer satisfaction after service failure and recovery. Journal of Service Research, 3(2), 121-137.
Morgan, S. L., \& Harding, D. J. (2006). Matching estimators of causal effects: Prospects and pitfalls in theory and practice. Sociological Methods \& Research, 35(1), 3-60.

Nadolny, T. L. (2020). Dangerous IKEA dressers recalled over risk of crashing onto children. USA Today. https:/eu.usatoday.com/story/ news/2020/03/04/ikea-recalls-kullen-dresser-over-danger-tip-ontochildren/4950532002/.

Nellis, S. (2017). Apple apologizes after outcry over slowed iPhones. Reuters. https://www.reuters.com/article/us-apple-batteries/appleapologizes-after-outcry-over-slowed-iphones-idUSKBN1EM20N.

Nichols, A. (2007). Causal inference with observational data. The Stata Journal, 7(4), 507-541.

Niedrich, R. W., Kiryanova, E., \& Black, W. (2005). The dimensional stability of the standards used in the disconfirmation paradigm. Journal of Retailing, 81(1), 49-57.

Oliver, R. L. (1980). A cognitive model of the antecedents and consequences of satisfaction decisions. Journal of Marketing Research, $17(4), 460-469$.

Oliver, R. L. (1997). Satisfaction: A behavioral perspective on the consumer. New York, McGraw Hill.

Oliver, R. L., \& DeSarbo, W. S. (1988). Response determinants in satisfaction judgments. Journal of Consumer Research, 14(4), 495-507.

Oliver, R., \& Westbrook, R. (1993). Profiles of consumer emotions and satisfaction in ownership and usage. Emotion, 6(13), 12-27.

Park, C. W., Eisingerich, A. B., \& Park, J. W. (2013). Attachmentaversion (AA) model of customer-brand relationships. Journal of Consumer Psychology, 23(2), 229-248.

Raithel, S., \& Hock, S. J. (2021). The crisis-response match: An empirical investigation. Strategic Management Journal, 42(1), 170-184.

Raithel, S., Mafael, A., \& Hock, S. J. (2021). The effects of brand equity and failure severity on remedy choice after a product recall, Journal of Product \& Brand Management, forthcoming.

Rhee, M., \& Haunschild, P. R. (2006). The liability of good reputation: a study of product recalls in the U.S. automobile industry. Organization Science, 17(1), 101-117.

Rindova, V. P., Williamson, I. O., Petkova, A. P., \& Sever, J. M. (2005). Being good or being known: An empirical examination of the dimensions, antecedents, and consequences of organizational reputation. Academy of Management Journal, 48(6), 1033-1049.

Roehm, M. L., \& Brady, M. K. (2007). Consumer responses to performance failures by high-equity brands. Journal of Consumer Research, 34(4), 537-545.

Rosenbaum, P. R., \& Rubin, D. B. (1983). Constructing a control group using multivariate matched sampling methods that incorporate the propensity score. The American Statistician, 39(1), 33-38.

Rubel, O., Naik, P. A., \& Srinivasan, S. (2011). Optimal advertising when envisioning a product-harm crisis. Marketing Science, 30(6), 10481065.

Siegel, D. S., \& Vitaliano, D. F. (2007). An empirical analysis of the strategic use of corporate social responsibility. Journal of Economics \& Management Strategy, 16(3), 773-792.

Smith, A. K., Bolton, R. N., \& Wagner, J. (1999). A model of customer satisfaction with service encounters involving failure and recovery. Journal of Marketing Research, 36(3), 356-372.

Stuart, E. A. (2010). Matching methods for causal inference: A review and a look forward. Statistical Science, 25(1), 1-21.

Thompson, D. V., Hamilton, R. W., \& Rust, R. T. (2005). Feature fatigue: When product capabilities become too much of a good thing. Journal of Marketing Research, 42(4), 431-442.

Walsh, M. F., Winterich, K. P., \& Mittal, V. (2010). Do logo redesigns help or hurt your brand? The role of brand commitment. Journal of Product \& Brand Management, 19(2), 76-84.

Weun, S., Beatty, S. E., \& Jones, M. A. (2004). The impact of service failure severity on service recovery evaluations and post-recovery relationships. Journal of Services Marketing, 18(2), 133-146. 
Zhao, Y., Zhao, Y., \& Helsen, K. (2011). Consumer learning in a turbulent market environment: Modeling consumer choice dynamics after a product-harm crisis. Journal of Marketing Research, 48(2), 255267.

Eilert, M., Jayachandran, S., Kalaignanam, K., \& Swartz, T. A. (2017). Does it pay to recall your product early? An empirical investigation in the automobile industry. Journal of Marketing, 81(3), 111-129

Liu, Y., \& Shankar, V. (2015). The dynamic impact of product-harm crises on brand preference and advertising effectiveness: An empirical analysis of the automobile industry. Management Science, 61(10), 2514-2535

Hock, S. J., \& Raithel, S. (2020). Managing negative celebrity endorser publicity: How announcements of firm (non) responses affect stock returns. Management Science, 66(3), 1473-1495.

Publisher's note Springer Nature remains neutral with regard to jurisdictional claims in published maps and institutional affiliations. 